\title{
From saturated to unsaturated conditions and vice versa
}

\author{
Martí Lloret-Cabot $^{1,4}$ (i) Simon J. Wheeler ${ }^{1} \cdot$ Jubert A. Pineda $^{2}$. \\ Enrique Romero $^{3} \cdot$ Daichao Sheng $^{2}$
}

Received: 3 March 2017 / Accepted: 11 July 2017/Published online: 5 August 2017

(c) The Author(s) 2017. This article is an open access publication

\begin{abstract}
Representing transitions between saturated and unsaturated conditions, during drying, wetting and loading paths, is a necessary step for a consistent unification between saturated and unsaturated soil mechanics. Transitions from saturated to unsaturated conditions during drying will occur at a nonzero air-entry value of suction, whereas transitions from unsaturated to saturated conditions during wetting or loading will occur at a lower nonzero air-exclusion value of suction. Air-entry and airexclusion values of suction for a given soil will differ (representing hysteresis in the retention behaviour) and both are affected by changes in the dry density of the soil or by the occurrence of plastic volumetric strains. The paper demonstrates, through model simulations and comparison with experimental data from the literature (covering drying, wetting and loading tests), that the Glasgow Coupled Model (GCM), a coupled elasto-plastic constitutive model covering both mechanical and retention behaviour, represents transitions between unsaturated and saturated behaviour in a consistent fashion. Key aspects of the GCM are the use of Bishop's stress tensor for mechanical behaviour, the additional influence of degree of
\end{abstract}

Martí Lloret-Cabot: Formerly University of Newcastle, Australia.

Martí Lloret-Cabot

Marti.Lloret-Cabot@glasgow.ac.uk

1 University of Glasgow, School of Engineering, Rankine Building, Glasgow G12 8LT, UK

2 University of Newcastle, Building EA, Callaghan, NSW 2308, Australia

3 Universitat Politècnica de Catalunya, Jordi Girona 1-3, Mòdul D2, 08034 Barcelona, Spain

4 University of Newcastle, Newcastle, Australia saturation on mechanical yielding, inclusion of hysteresis in the retention behaviour, and the role of plastic volumetric strains (and not total volumetric strains) in the description of the water retention response. The success of the GCM in representing consistently transitions between saturated and unsaturated conditions, together with subsequent mechanical and retention responses, demonstrates the potential of this coupled constitutive model for numerical modelling of boundary value problems involving saturated and unsaturated conditions.

Keywords Coupling · Degree of saturation · De-saturation · De-saturation line $\cdot$ Dry density $\cdot$ Mechanical yielding ·

Mechanical behaviour - Plastic volumetric strains .

Retention hysteresis · Saturation · Saturation line .

Water retention

\section{List of symbols}

$\sigma_{i j} \quad$ Total stress tensor

$\sigma_{i j}^{\prime} \quad$ Saturated effective stress tensor

$\sigma_{i j}^{*} \quad$ Bishop's stress tensor

$\bar{\sigma}_{i j} \quad$ Net stress tensor

$\delta_{i j} \quad$ Kronecker's delta

$p \quad$ Mean total stress

$p^{\prime} \quad$ Saturated mean effective stress

$p^{*} \quad$ Mean Bishop's stress

$\bar{p} \quad$ Mean net stress

$\sigma_{\mathrm{v}} \quad$ Total vertical stress

$\sigma_{\mathrm{v}}^{\prime} \quad$ Saturated vertical effective stress

$\sigma_{\mathrm{v}}^{*} \quad$ Vertical Bishop's stress

$\bar{\sigma}_{\mathrm{v}} \quad$ Vertical net stress

$s^{*} \quad$ Modified suction

$s \quad$ Matric suction

$u_{\mathrm{a}} \quad$ Pore air pressure 
$u_{\mathrm{w}} \quad$ Pore water pressure

$S_{r} \quad$ Degree of saturation

$\chi \quad$ Bishop's weighting factor

$w \quad$ Water content

$n \quad$ Porosity

e Void ratio

$v \quad$ Specific volume

$p_{0}^{\prime} \quad$ Saturated mechanical yield stress

$s_{\mathrm{e}}^{*} \quad$ Air-entry value of $s^{*}$

$s_{\mathrm{ex}}^{*} \quad$ Air-exclusion value of $s^{*}$

$p_{0}^{*} \quad$ Hardening parameter for the mechanical yield surface

$s_{1}^{*} \quad$ Hardening parameter for the wetting retention yield surface

$s_{2}^{*} \quad$ Hardening parameter for the drying retention yield surface

$\varepsilon_{\mathrm{V}} \quad$ Total volumetric strain

$\varepsilon_{\mathrm{v}}^{\mathrm{e}} \quad$ Elastic component of volumetric strain

$\varepsilon_{\mathrm{v}}^{\mathrm{p}} \quad$ Plastic component of volumetric strain

$N$ Intercept of the saturated normal compression line in the $v: \ln p^{\prime}$ plane

$\kappa \quad$ Gradient of elastic swelling lines in the $v: \ln p^{\prime}$ plane

$\lambda$ Gradient of normal compression lines in the $v: \ln p^{\prime}$ plane for tests involving no plastic changes of $S_{r}$ (such as saturated tests)

$k_{1} \quad$ Coupling parameter controlling how water retention yielding influences mechanical behaviour

$k_{2} \quad$ Coupling parameter controlling how mechanical yielding influences water retention behaviour

$\kappa_{\mathrm{s}} \quad$ Gradient of elastic scanning curves in the $S_{r}: \ln s^{*}$ plane

$\lambda_{\mathrm{s}} \quad$ Gradient of main wetting/drying curves in the $S_{r}: \ln s^{*}$ plane for tests involving no plastic volumetric strain

$N^{*}$ Intercept of the unsaturated isotropic normal compression planar surface for $v$ in the $v: \ln p^{*}: \ln s^{*}$ space

$\lambda^{*} \quad$ Gradient of the unsaturated isotropic normal compression planar surface for $v$ in the $v: \ln p^{*}: \ln s^{*}$ space

$k_{1}^{*} \quad$ Second gradient of the unsaturated isotropic normal compression planar surface for $v$ in the $v: \ln p^{*}: \ln s^{*}$ space

$\Omega^{*} \quad$ Intercept of the isotropic normal compression planar surface for $S_{r}$ in the $S_{r}: \ln p^{*}: \ln s^{*}$ space

$\lambda_{\mathrm{s}}^{*} \quad$ Gradient of the isotropic normal compression planar surface for $S_{r}$ in the $S_{r}: \ln p^{*}: \ln s^{*}$ space

$k_{2}^{*} \quad$ Second gradient of the isotropic normal compression planar surface for $S_{r}$ in the $S_{r}: \ln p^{*}: \ln s^{*}$ space

$R \quad$ Ratio of $s_{2}^{*}$ to $s_{1}^{*}$
Abbreviations
GCM Glasgow Coupled Model
M Mechanical yield surface
WR Wetting retention yield surface

DR Drying retention yield surface

BBM Barcelona Basic Model

LC Loading collapse yield curve

MW Mechanical wetting curve

MD Mechanical drying curve

ncl Normal compression line

url Unloading-reloading line

OCR Overconsolidation ratio

NC Normally consolidated

OC Overconsolidated

1D One-dimensional

\section{Introduction}

Consistent representation of the occurrence of de-saturation and saturation is potentially of great importance in many practical geotechnical problems, because the mechanical response of a saturated soil (or a soft-rock) under a given stress path can be very different from that of the same material under unsaturated conditions (e.g. $[71,72])$. Proper distinction between saturated and unsaturated states is not only relevant for a more comprehensive representation of the occurrence and magnitude of plastic volumetric compression (e.g. [3, 5, 6, 10, 20, 28, 33, $44,65,66,76])$ but also for a more reliable prediction of shear strength (e.g. [11, 12, 22, 48, 73, 79]). Indeed, both of these aspects of mechanical behaviour are influenced by the evolution of degree of saturation (as well as by suction, through the water retention response) and may show important differences whether a soil is fully saturated or not.

Consistent representation of transitions between saturated and unsaturated conditions is also important from a theoretical perspective, because handling correctly the stress states at de-saturation and at saturation is an essential ingredient in a constitutive model aimed at representing realistically soil behaviour. Proper modelling of such transitions (together with the ability of the model to represent also the subsequent soil response under either unsaturated or saturated states) is hence of fundamental interest; firstly, to understand more fully the material behaviour by means of a constitutive model and, secondly, for the practical use of such constitutive model in finite element analysis to solve boundary value problems involving both unsaturated and saturated conditions.

Unified modelling of unsaturated and saturated soil behaviour (including consistent representations of transitions between unsaturated and saturated states) is achieved in this paper through the use of a coupled elasto-plastic constitutive model that naturally incorporates the effects of dry density on the hysteretic response of the water 
retention. The model adopted is the Glasgow Coupled Model (GCM) [41, 78], which is intended to represent the response of unsaturated low-activity soils where capillary effects dominate, hence excluding adsorption effects on water retention properties (i.e. with no consideration of residual degree of saturation, see [81]) and soils containing highly expansive clay minerals. No account is taken of any effects specifically attributable to a bi-modal pore size distribution. Detailed descriptions of the mechanical and water retention aspects related to the evolving nature of the microstructure of compacted double-porosity clayey soils can be found elsewhere (e.g. [4, 6, 19, 46, 52]). Finally, anisotropy of soil behaviour is not considered in the paper, with the aim of focusing on saturation and de-saturation processes in soils without important direction-dependent response.

The process of de-saturation (from a saturated state to an unsaturated state) is examined in the paper by investigation of the experimental tests of Boso [13], which involved airdrying of reconstituted samples of Barcelona clayey silt. De-saturation tests on a reconstituted soil are particularly convenient, because it is easy to ensure that soil samples are completely saturated at the start of tests (something more difficult to achieve when dealing with natural or compacted soils). In addition, the pore size distribution generated in reconstituted soil samples prepared from slurry is predominantly mono-modal, which simplifies greatly the interpretation of the experimental results given by a constitutive model. The experiments reported by Boso [13] are particularly interesting, because the air-drying paths were applied under different levels of pre-consolidation, and hence, the influence of mechanical behaviour on de-saturation can be analysed in detail. The investigation of these tests in the context of the GCM suggests that the mechanical response of a soil on drying is essentially dependent on the overconsolidation ratio of the soil at the start of the drying which, as expected, also affects the suction value at which the soil de-saturates (i.e. the airentry point).

The transition in the reverse direction (from unsaturated to saturated states) is studied in the paper for various soils, including Barcelona clayey silt [13], Speswhite kaolin [63] and London clay [45]. In this case, the process of saturation is studied not only upon wetting but also during different types of loading, including compression tests under constant water content and compression tests at constant suction. The study of these experimental data shows how helpful it is to incorporate degree of saturation in the formulation of a constitutive model. Degree of saturation plays important roles in the GCM, appearing within one of the stress state variables and also separately influencing mechanical yielding. This results in improved representation of transitions between saturated and unsaturated states and consistent unification of saturated and unsaturated soil behaviour.

\section{The Glasgow Coupled Model}

The results presented in this study refer to isotropic and oedometric stress states but the conclusions found are equally applicable to general stress states. Details of the extended formulation of the GCM (applicable to general stress states) can be found elsewhere (e.g. [38]).

The constitutive stress variables of the GCM for isotropic stress states are the mean Bishop's stress $p^{*}$ (sometimes called average skeleton stress, [31]) and the modified suction $s^{*}$ :

$p^{*}=p-S_{r} u_{\mathrm{w}}-\left(1-S_{r}\right) u_{\mathrm{a}}=\bar{p}+S_{r} s$

$s^{*}=n\left(u_{\mathrm{a}}-u_{\mathrm{w}}\right)=n s$

where $p$ is mean total stress, $u_{\mathrm{w}}$ the pore water pressure, $u_{\mathrm{a}}$ the pore air pressure, $n$ the porosity, $\bar{p}$ the mean net stress and $s$ the matric suction. Note that in Eq. 1, the weighting factor $\chi$ proposed in Bishop's original expression [8] is replaced by the degree of saturation, as suggested in [58]. $p^{*}$ and $s^{*}$ are work-conjugate with volumetric strain increment $\mathrm{d} \varepsilon_{\mathrm{v}}$ and decrement of degree of saturation- $\mathrm{d} S_{r}$, respectively [30].

The GCM uses elasto-plasticity to represent the development of strains (mechanical behaviour), including variations of specific volume $v$, i.e. $\mathrm{d} \varepsilon_{\mathrm{v}}=-\mathrm{d} v / v$. Elastoplasticity is also used to represent changes of degree of saturation (water retention behaviour).

The elastic component of the total variation of $v$ is assumed to be proportional to the logarithmic variation of mean Bishop's stress $p^{*}$. Such proportionality is controlled by a soil parameter $\kappa$, which corresponds to the gradient of unloading-reloading lines in the $v: \ln p^{*}$ plane. When a soil saturates at $S_{r}=1$, the mean Bishop's stress $p^{*}$ equals the saturated mean effective stress $p^{\prime}=p-u_{w}$, even if matric suction $s$ is not zero (see Eq. 1), and, in this way, the elastic response naturally converges to the conventional elastic relationship between $v$ and $p^{\prime}$ for saturated critical state models [56].

In the original formulation of the GCM by Wheeler et al. [78], the elastic component of the total variation of $S_{r}$ is assumed to be proportional to the logarithmic variation of modified suction $s^{*}$, and such proportionality is controlled by the soil parameter $\kappa_{\mathrm{s}}$ (which corresponds to the gradient of retention scanning lines in the $S_{r}: \ln s^{*}$ plane). In situations where transitions between unsaturated and saturated conditions occur, it is recommended to use $\kappa_{\mathrm{s}}=0$ [41]. This recommendation is adopted throughout the remainder of this paper. 
A single mechanical yield surface $M$ is used to describe the occurrence of plastic volumetric strains (mechanical behaviour) potentially occurring during loading, wetting, and drying paths [39]. Two additional yield surfaces are employed to describe the occurrence of plastic changes of degree of saturation (retention behaviour). Yielding on the wetting retention yield surface WR corresponds to plastic increases in $S_{r}$, and yielding on the drying retention surface DR corresponds to plastic decreases in $S_{r}$. Two coupling parameters, $k_{1}$ and $k_{2}$, control the coupled movements between these three yield surfaces, representing the influences between mechanical and retention behaviour during yielding [78].

The initial locations of $\mathrm{M}$ and WR yield surfaces are defined by initial values of the hardening parameters $p_{0} *$ and $s_{1}{ }^{*}$, respectively. The location of the DR surface is given by the value of the hardening parameter $s_{2}{ }^{*}$, which corresponds to $R \cdot s_{1}{ }^{*}$, where $R$ is a soil parameter to represent the degree of hysteresis in the water retention response, i.e. $R=1$ means no hysteresis.

\subsection{Yielding on the mechanical yield surface alone}

For fully saturated isotropic loading involving yielding on the $\mathrm{M}$ yield surface, the total variation of specific volume (including elastic and plastic components) corresponds to variation of $v$ on a unique straight line of gradient $\lambda$ and intercept $N$ in the $v: \ln p^{*}$ plane (see Fig. 1), consistent with the existence and form of the conventional saturated normal compression line (ncl) in the $v: \ln p^{\prime}$ plane [56]. In the GCM, isotropic loadings under unsaturated conditions involving yielding on only the $\mathrm{M}$ surface (i.e. with no plastic changes of $S_{r}$ ) correspond to variations of $v$ on unique straight lines in the $v: \ln p^{*}$ plane, all parallel to the saturated ncl, as shown in Fig. 1. The assumption of $\kappa_{\mathrm{s}}=0$ adopted in this paper means that each of these lines corresponds to a specific constant value of $S_{r}$, as indicated by the labels $\left(S_{r}\right)_{i}$ for $i=\mathrm{A}, \mathrm{B}$ and $\mathrm{C}$ in Fig. 1.

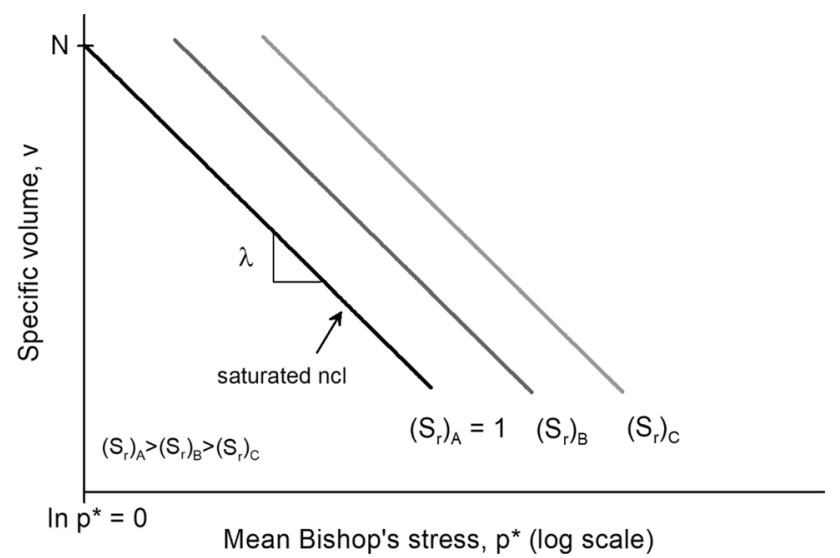

Fig. 1 Typical model responses during yielding on only M surface
The constant $S_{r}$ normal compression lines plotted in Fig. 1 (which involve yielding on only the $\mathrm{M}$ yield surface) do not correspond to conventional constant suction normal compression lines typically presented in the literature $\left(S_{r}\right.$ will be varying in these constant $s$ tests). Lloret-Cabot et al. [41] showed that the GCM predicts that normal compression lines from compression tests conducted at constant modified suction $s^{*}$ will involve yielding on both $\mathrm{M}$ and WR yield surfaces and will take the form of straight lines of a gradient $\lambda^{*}$ in the $v: \ln p^{*}$ plane (where $\lambda^{*}$ is greater than $\lambda$, see Appendix), and each of these lines converges with the saturated ncl shown in Fig. 1 at an air-exclusion point. Constant $s$ normal compression lines are rather similar to constant $s^{*}$ normal compression lines, and therefore the GCM predicts that the normal compression lines seen in conventional constant suction tests reported in the literature are approximately straight lines with a gradient slightly greater than $\lambda^{*}$ in the $v: \ln p^{*}$ plane until $S_{r}=1$ [37, 41]. This is consistent with experimental observations (e.g. [34, 45, 50, 51, 59, 63]).

\subsection{Yielding on the wetting retention yield surface alone}

Figure 2 shows the retention response of a wetting path conducted with the initial state on the WR yield surface, but with three different initial positions of the $M$ surface (i.e. $M_{A}, M_{B}$ and $\mathrm{M}_{\mathrm{C}}$ in Fig. $2 \mathrm{a}$ ). Wetting in all three cases involves yielding on only the WR yield surface (with no plastic compression) until full saturation is reached at the air-exclusion point $\mathrm{S}_{\mathrm{A}}, \mathrm{S}_{\mathrm{B}}$ or $\mathrm{S}_{\mathrm{C}}$ (Fig. 2b). Hence, in the context of the GCM, the corresponding evolution of $\mathrm{S}_{r}$ until saturation corresponds to a main wetting curve. This model response is represented by the continuous lines in Fig. 2b, with each main wetting curve corresponding to a straight line of gradient $\lambda_{\mathrm{s}}$ when plotted in the $S_{r}: \ln s^{*}$ retention plane.

Each of the continuous lines in Fig. 2b represents a main wetting curve for a wetting path conducted at a given state of plastic volumetric compression (indicated in the figure by $\left(\varepsilon_{\mathrm{v}}^{\mathrm{p}}\right)_{i}$ for $i=\mathrm{A}, \mathrm{B}$ and $\mathrm{C}$ ), as it is through the occurrence of plastic volumetric strains (and not total volumetric strain) that the GCM represents the influence of mechanical behaviour on the water retention response of the soil [40]. Hence, the air-exclusion value of modified suction $s_{\mathrm{ex}}^{*}$, defining the position of each main wetting curve in Fig. 2b, is linked to the value of $\left(\varepsilon_{\mathrm{v}}^{\mathrm{p}}\right)$, which is in turn linked to the amount of mechanical yielding prior to wetting, as illustrated by the different initial positions of the $M$ yield surface at the start of wetting $\left(\mathrm{M}_{\mathrm{A}}, \mathrm{M}_{\mathrm{B}}\right.$ and $\mathrm{M}_{\mathrm{C}}$ in Fig. 2a).

During wetting involving yielding on the WR surface alone, coupled inward movements of the $M$ yield surface 

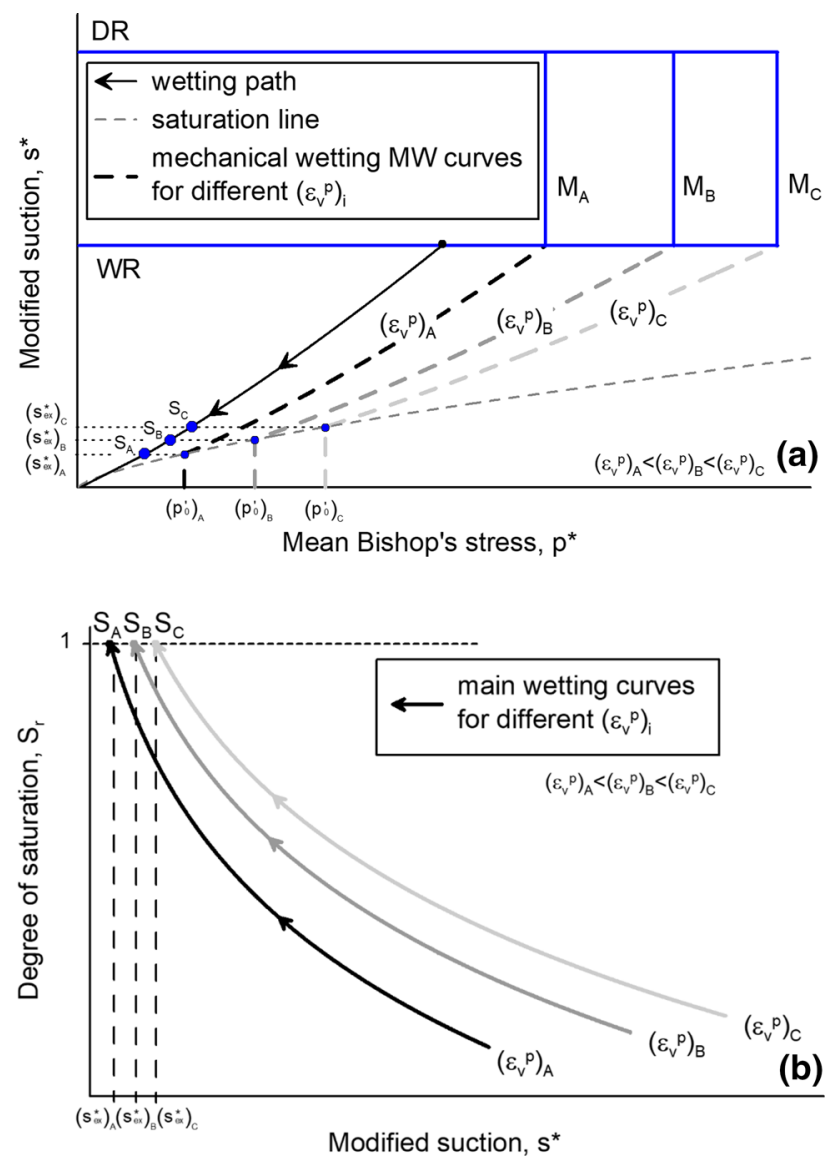

Fig. 2 Typical model responses during yielding on only WR surface: a wetting path in the $s^{*}: p^{*}$ plane; $\mathbf{b}$ water retention behaviour

are produced, and hence the value of the mechanical yield stress $p_{0}^{*}$ reduces. This represents the reduction in stability of the soil skeleton as a consequence of the loss of meniscus water bridges during yielding on the WR surface [78]. Plots of the variation of $p_{0}^{*}$ with $s^{*}$ during the three wetting processes illustrated in Fig. 2 (with the three different initial positions of the M surface) are shown by the thicker dashed lines in Fig. 2a. Each of these lines corresponds to a given value of $\left(\varepsilon_{\mathrm{v}}^{\mathrm{p}}\right)$ (see the labels $\left(\varepsilon_{\mathrm{v}}^{\mathrm{p}}\right)_{i}$ for $i=\mathrm{A}, \mathrm{B}$ and $\mathrm{C}$ in Fig. 2a) and is referred to hereafter as a mechanical wetting MW curve. Each of the MW curves in Fig. 2a is associated with the corresponding main wetting curve (with the same value of $\left(\varepsilon_{\mathrm{v}}^{\mathrm{p}}\right)$ ) in Fig. $2 \mathrm{~b}$.

The MW curve acts rather like a yield curve and corresponds to the onset of collapse compression during wetting, although strictly it is the M curve that is the yield curve, and the MW curve simply tracks the coupled movement of the $\mathrm{M}$ curve during yielding on the WR surface alone. Interestingly, the form of the MW curve illustrated in Fig. 2a resembles the conventional loading collapse LC yield curve of the Barcelona Basic Model (BBM) of Alonso et al. [2]. Similar forms of the LC yield curve have also been proposed in many subsequent models, expressing the variation of the pre-consolidation stress in terms of suction (e.g. [36, 62, 77]) or degree of saturation (e.g. $[24,26,32,67,80])$.

There are, however, important advantages of the MW curve in the GCM over the LC yield curve in most other constitutive models. One of these advantages is described here and another is discussed in the following section.

The first advantage of the MW curve in the GCM over the LC yield curve in most other constitutive models relates to the fact that saturated conditions can occur at nonzero values of suction, and yielding should then be governed by the saturated effective stress (e.g. [28, 29, 59, 60, 62]). This is difficult to capture with a conventional LC yield curve, as it would typically require a dramatic change of yield curve inclination at transitions between unsaturated and saturated conditions. In contrast, Lloret-Cabot et al. [41] demonstrated that it occurs naturally in the GCM, because coupled inward movement of the $\mathrm{M}$ surface during wetting ceases when the soil reaches a saturated condition and hence the continuation of the MW curve is simply a line of constant $p_{0}^{*}$ once the soil is saturated. This is illustrated by the vertical lower sections of the three MW curves shown in Fig. 2a, at values of $s^{*}$ below the relevant air-exclusion value $s_{\mathrm{ex}}^{*}$. Inspection of Fig. 2a shows that the mechanical yield stress $p_{0}^{*}$ at $S_{r}=1$ determines the position of the entire MW curve, and the value of $p_{0}^{*}$ remains constant for $s^{*} \leq s_{\mathrm{ex}}^{*}$. This is because $p_{0}^{*}$ is equal to the yield value of mean effective stress $p_{0}^{\prime}$ when $S_{r}=1$ (Eq. 1). Hereafter, the mechanical yield stress at saturation is referred to as $p_{0}^{\prime}$, and $p_{0}^{*}$ will only refer to unsaturated conditions.

\subsection{Yielding on the drying retention yield surface alone}

Due to the incorporation of hysteresis in the representation of the water retention behaviour, each constant $\left(\varepsilon_{\mathrm{v}}^{\mathrm{p}}\right)$ main wetting curve of the GCM described in the previous section has an associated parallel main drying curve in the $S_{r}: \ln s^{*}$ plane, to represent plastic decreases in $S_{r}$ during drying stress paths that involve yielding on only the DR surface (i.e. with no plastic compression). Equivalent to the previous comments on wetting, each of these main drying curves corresponds to the water retention response on drying at a given level of $\left(\varepsilon_{\mathrm{v}}^{\mathrm{p}}\right)$ (that resulted from a specific history of mechanical yielding before drying). Similar to the discussion of Fig. 2, the state of plastic volumetric strain $\left(\varepsilon_{\mathrm{v}}^{\mathrm{p}}\right)$ at the start of drying controls the value of modified suction at de-saturation $s_{\mathrm{e}}^{*}$ (the air-entry point) which, in turn, fixes the position of an entire main drying curve in the retention plane. 
Furthermore, each main drying curve of the GCM is associated with a corresponding curve in the $s^{*}: p^{*}$ plane (referred to hereafter as the mechanical drying MD curve), which tracks how the mechanical yield stress $p_{0}^{*}$ increases with increasing modified suction during a drying process that involves yielding on only the DR yield surface. This represents the coupled outward movement of the $\mathrm{M}$ yield surface which occurs in the GCM during yielding on the DR surface and which models the increasing stability of the soil skeleton as the number of meniscus water bridges increases during drying [78].

The MD curve is associated with a drying process at a particular value of $\left(\varepsilon_{\mathrm{v}}^{\mathrm{p}}\right)$ (i.e. without yielding on the $\mathbf{M}$ surface), and it describes the onset of plastic shrinkage during drying. The role of the MD curve during drying is directly equivalent to the role of the MW curve during wetting. If there is no retention hysteresis $(R=1)$, the MD and MW curves coincide, whereas the MD and MW curves are different if retention hysteresis is included $(R>1)$ [41]. Tamagnini [67] argued in this context, that the occurrence of retention hysteresis in unsaturated soils (e.g. $[17,48,51,55,68])$ suggests the existence of a second mechanical yield function (in addition to the LC curve) for the evolution of the mechanical yield stress on drying. This additional yield curve emerges naturally in the GCM as consequence of the retention hysteresis incorporated in the model and corresponds to the MD curve. This represents a second advantage of the MW and MD curves in the GCM (both simply arising from coupled movements of a single $M$ yield surface) over the LC yield surface in more conventional constitutive models for unsaturated soils.

\section{Saturation and de-saturation lines}

The degree of saturation is the natural variable to represent the occurrence of full saturation, as it is only when $S_{r}=1$ that all voids are entirely filled with water. The values of suction corresponding to the occurrence of saturation (airexclusion point) or, equivalently, the values of suction at which de-saturation occurs from a fully saturated state (airentry point) depend on the previous stress history of the soil, and this dependency should be in correspondence with how a given model represents the influence of dry density on water retention. Such influence of mechanical behaviour on the water retention has been observed and discussed in a large number of experimental tests (e.g. $[15,52-55,68,78])$ and is often represented in a model by a shift of the main wetting and main drying retention curves to higher values of suction when the void ratio decreases ([25, 36, 43, 49, 61, 62, 74], among others). The experimental data investigated in Tarantino [68] shows that not only should this shift affect the unsaturated part of the water retention response, but it should also have some influence on the values of suction at which de-saturation and saturation are predicted (i.e. air-entry and air-exclusion points, respectively).

The influence of dry density on the predicted states at which transitions between saturated and unsaturated conditions occur should be formulated in a model in a way that is consistent with the occurrence of a unique saturated normal compression line. In this context, when modelling soils under saturated conditions that may potentially desaturate, it will still be necessary to account for how stress history affects the water retention response (including airentry and air-exclusion points) because for any subsequent drying, $S_{r}$ should remain equal to one for all values of suction lower than the air-entry point corresponding to the past stress history.

The occurrence of different air-entry and air-exclusion values of suction as a consequence of a different dry density suggests that the past history of mechanical yielding must play a central role in modelling transitions between saturated and unsaturated conditions. In the GCM, the influence of dry density on the retention response is represented through the influence of plastic volumetric strains (see, for example, the main wetting curves in Fig. 2b). This assumption provides, naturally, a consistent link between the occurrence of de-saturation/saturation and the past history of mechanical yielding, predicting larger air-entry/air-exclusion values of $s^{*}$ if greater amounts of mechanical yielding (corresponding to greater values of $\left.\left(\varepsilon_{\mathrm{v}}^{\mathrm{p}}\right)\right)$ have occurred.

This way of coupling mechanical and retention behaviour in the GCM contrasts with most other coupled constitutive models for unsaturated soils, as the majority of them describe the impact of mechanical behaviour on retention behaviour through total volumetric strain, rather than only plastic volumetric strain (e.g. $[5,19,25,36,43,49,61])$. The use of plastic volumetric strain $\left(\varepsilon_{\mathrm{v}}^{\mathrm{p}}\right)$ to describe the influence of mechanical behaviour on water retention behaviour in the GCM, combined with the use of the Bishop's stress tensor as a stress state variable in the constitutive model, means that the GCM represents the occurrence of saturation/de-saturation in such a way that the predicted form and location of the normal compression line under saturated conditions are unique (unaffected by any previous stress history involving both saturated and unsaturated conditions). This is because plastic volumetric strain (rather than total volumetric strain) is what controls the evolution of the saturated mechanical yield stress, via a hardening law.

The GCM predicts that transitions from saturated to unsaturated conditions can only occur while on the DR 
yield surface (but not necessarily on the M surface). Similarly, transitions from unsaturated to saturated conditions occur on the WR yield surface (but not necessarily on the M surface). Analytical expressions for de-saturation and saturation lines, relating air-entry and air-exclusion values of $s^{*}\left(s_{\mathrm{e}}^{*}\right.$ and $s_{\mathrm{ex}}^{*}$, respectively) to the corresponding values of mechanical yield stress $p_{0}^{\prime}$ at the point of de-saturation or saturation, were derived by [41] as:

$s_{\mathrm{e}}^{*}=R \exp \left(\frac{\Omega^{*}-1}{\lambda_{\mathrm{s}}^{*}}\right)\left(p_{0}^{\prime}\right)^{k_{2}}$

$s_{\mathrm{ex}}^{*}=\exp \left(\frac{\Omega^{*}-1}{\lambda_{\mathrm{s}}^{*}}\right)\left(p_{0}^{\prime}\right)^{k_{2}}$

where $\lambda_{\mathrm{s}}^{*}$ and $\Omega^{*}$ are soil constants (see Appendix). Figure 3 illustrates the form of Eqs. 3 and 4 in the $s^{*}: p_{0}^{\prime}$ plane.

The de-saturation and saturation lines defined by Eqs. 3 and 4 can also be plotted in the $s^{*}: p^{*}$ plane. Note that, in this case, de-saturation or saturation will not necessarily occur when the drying or wetting stress path in the $s^{*}: p^{*}$ plane reaches the de-saturation or saturation line, because Eqs. 3 and 4 are written in terms of the mechanical yield stress at de-saturation or saturation $p_{0}^{\prime}$, rather than the value of mean effective stress at de-saturation or saturation $p^{\prime}$. This means that de-saturation or saturation will occur when the stress path reaches the corresponding de-saturation or saturation line if the soil is in a normally consolidated state (on the $\mathrm{M}$ yield surface) at this point $\left(p^{\prime}=p_{0}^{\prime}\right.$ ), whereas desaturation or saturation will occur with the stress state to the left of the corresponding de-saturation or saturation line in the $s^{*}: p^{*}$ plane if the soil is in an overconsolidated state at this point $\left(p^{\prime}<p_{0}^{\prime}\right)$. This is illustrated in Fig. 2a, where the saturation points $\left(\mathrm{S}_{\mathrm{A}}, \mathrm{S}_{\mathrm{B}}\right.$ and $\left.\mathrm{S}_{\mathrm{C}}\right)$ for the three wetting tests shown in Fig. 2 lie to the left of the saturation line, because, in all three cases, the soil is in an overconsolidated state (not on the M yield surface) at the point of saturation. Note that, in all cases, saturation corresponds to the value of modified suction at the intersection of the MW curve

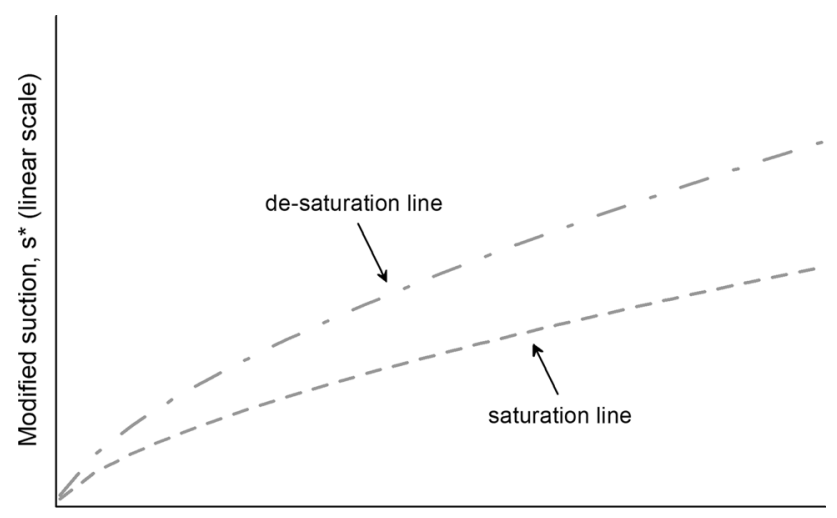

Mechanical yield stress at saturation/desaturation, $\mathrm{p}_{0}^{\prime}$ (linear scale)

Fig. 3 Predicted saturation and de-saturation lines with the saturation line (see Fig. 2a), or during a drying test, de-saturation corresponds to the intersection of the MD curve with the de-saturation line.

\section{Influence of plastic volumetric strain on retention behaviour}

To illustrate further how the GCM couples the influence of dry density (or, more strictly, plastic volumetric strain) on water retention behaviour, this section discusses the model responses for wetting or drying tests if plastic volumetric strains are also occurring (collapse compression during wetting or plastic shrinkage during drying).

\subsection{Water retention response if collapse compression occurs during wetting}

Figure 4a shows the stress path of a typical conventional wetting test (i.e. decrease in matric suction at constant mean net stress) plotted in the $s^{*}: p^{*}$ plane (see the thick continuous line $\mathrm{AB}$ ). The initial positions of the three yield surfaces are labelled in the figure with the subscript A. The initial stress state at $\mathrm{A}$ is on the WR yield surface but inside
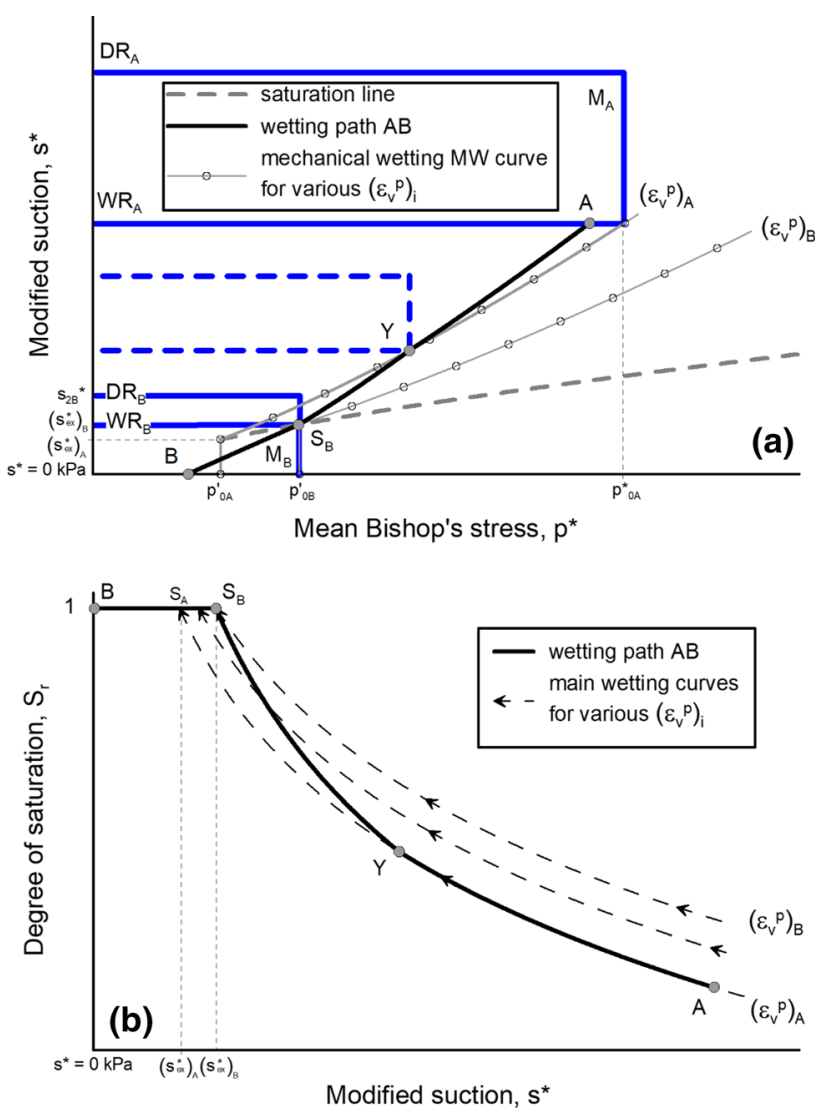

Fig. 4 Typical model response during a drying path at constant net stress: a stress path in the $s^{*}: p^{*}$ plane; $\mathbf{b}$ water retention behaviour 
the $M$ yield surface. During wetting, coupled inward movement of the $\mathrm{M}$ yield surface occurs (as indicated by the MW curve labelled $\left(\varepsilon_{\mathrm{v}}^{\mathrm{p}}\right)_{\mathrm{A}}$ in Fig. 4a), such that the wetting stress path reaches the $M$ yield surface at point $Y$ (the intersection of the stress path with the MW curve), because from $\mathrm{A}$ to $\mathrm{Y}$ the coupled inward movement of the M surface occurs faster than the leftward movement of the stress point [39].

From $\mathrm{Y}$ until achieving full saturation at point $S_{B}$ in Fig. $4 \mathrm{a}$, simultaneous yielding on $\mathrm{M}$ and WR surfaces is predicted, causing plastic volumetric strains (collapse compression) and plastic increases in $\mathrm{S}_{r}$. In this case, saturation at $\mathrm{S}_{\mathrm{B}}$, at an air-exclusion value of modified suction $s_{\mathrm{exB}}^{*}$, coincides with the intersection of the wetting stress path with the saturation line (see Fig. 4a), because the soil is in a normally consolidated condition (on the M yield surface) at this point. From $S_{B}$ to the final state at $B$ in Fig. $4 \mathrm{a}$, the soil is in a saturated condition, and there are no further plastic increases in $S_{r}$, implying no further movements of the WR and DR yield surfaces and no further coupled inward movement of the $\mathrm{M}$ yield surface. This final stage of wetting corresponds to elastic unloading of a saturated soil, as the pore water pressure is increased and the mean effective stress decreases.

The final positions of the three yield surfaces are shown in Fig. 4a (labelled with the subscript B), together with the final position of the MW curve (marked by the label $\left.\left(\varepsilon_{\mathrm{v}}^{\mathrm{p}}\right)_{\mathrm{B}}\right)$. Note that the expansion of the MW curve (from the initial position labelled $\left(\varepsilon_{\mathrm{v}}^{\mathrm{p}}\right)_{\mathrm{A}}$ to the final position labelled $\left.\left(\varepsilon_{\mathrm{v}}^{\mathrm{p}}\right)_{\mathrm{B}}\right)$ is equivalent to expansion of the LC yield curve during wetting-induced collapse compression in a conventional constitutive model for unsaturated soils. The value of saturated mechanical yield stress once the wetting is completed is given by $p_{\mathrm{OB}}^{\prime}$ (see Fig. 4a), whereas it would have been $p_{0 \mathrm{~A}}^{\prime}$ if no collapse compression had occurred during wetting.

The predicted water retention response during $\mathrm{AB}$ is shown in Fig. 4 b by a thick continuous line. The three thinner dashed lines also included in Fig. 4b show the form of the main wetting curve for different constant values of plastic volumetric strain, including those corresponding to the initial and final values of $\left(\varepsilon_{\mathrm{v}}^{\mathrm{p}}\right)$ (labelled $\left(\varepsilon_{\mathrm{v}}^{\mathrm{p}}\right)_{\mathrm{A}}$ and $\left.\left(\varepsilon_{\mathrm{v}}^{\mathrm{p}}\right)_{\mathrm{B}}\right)$. Note that from A to $\mathrm{Y}$ (while no yielding on the M surface is occurring) the predicted retention response follows the constant $\left(\varepsilon_{\mathrm{v}}^{\mathrm{p}}\right)$ main wetting curve corresponding to $\left(\varepsilon_{\mathrm{v}}^{\mathrm{p}}\right)_{\mathrm{A}}$, but the predicted retention curve from $Y$ to $S_{B}$ then deviates from a constant $\left(\varepsilon_{\mathrm{v}}^{\mathrm{p}}\right)$ main wetting curve, as yielding on the $M$ yield surface leads to the occurrence of plastic volumetric strain (collapse compression). In contrast, if no collapse compression had occurred during wetting, the retention response would have remained on the constant $\left(\varepsilon_{\mathrm{v}}^{\mathrm{p}}\right)$ main wetting curve corresponding to $\left(\varepsilon_{\mathrm{v}}^{\mathrm{p}}\right)_{\mathrm{A}}$ (see
Fig. 4b). This difference in behaviour is what would be expected experimentally, as observed, for example, in Monroy [45].

The small amount of elastic swelling predicted by the GCM during the final (saturated) stage of wetting (from $\mathrm{S}_{\mathrm{B}}$ to $\mathrm{B}$ in Fig. 4), after the previous collapse compression (from $\mathrm{Y}$ to $\mathrm{S}_{\mathrm{B}}$ ), is consistent with experimental observations of wetting-induced swelling subsequent to collapse compression (e.g. [9, 14, 45, 64, 77]).

\subsection{Water retention response if plastic shrinkage occurs during drying}

Figure 5 shows the behaviour predicted by the GCM during a conventional drying path $\mathrm{CD}$ conducted at constant mean net stress, in which plastic shrinkage occurs during the later part YD of the drying path. Note that the plot includes the simulation of a small unloading $\mathrm{BC}$ at constant zero suction prior to drying, conducted immediately after the wetting $A B$ discussed in the previous subsection. This is to provide an example where there is no occurrence of any plastic compression during the initial saturated stages of the simulated drying path (see Fig. 5a). The stress state at $\mathrm{C}$ is under saturated conditions (see Fig. 5b), and the

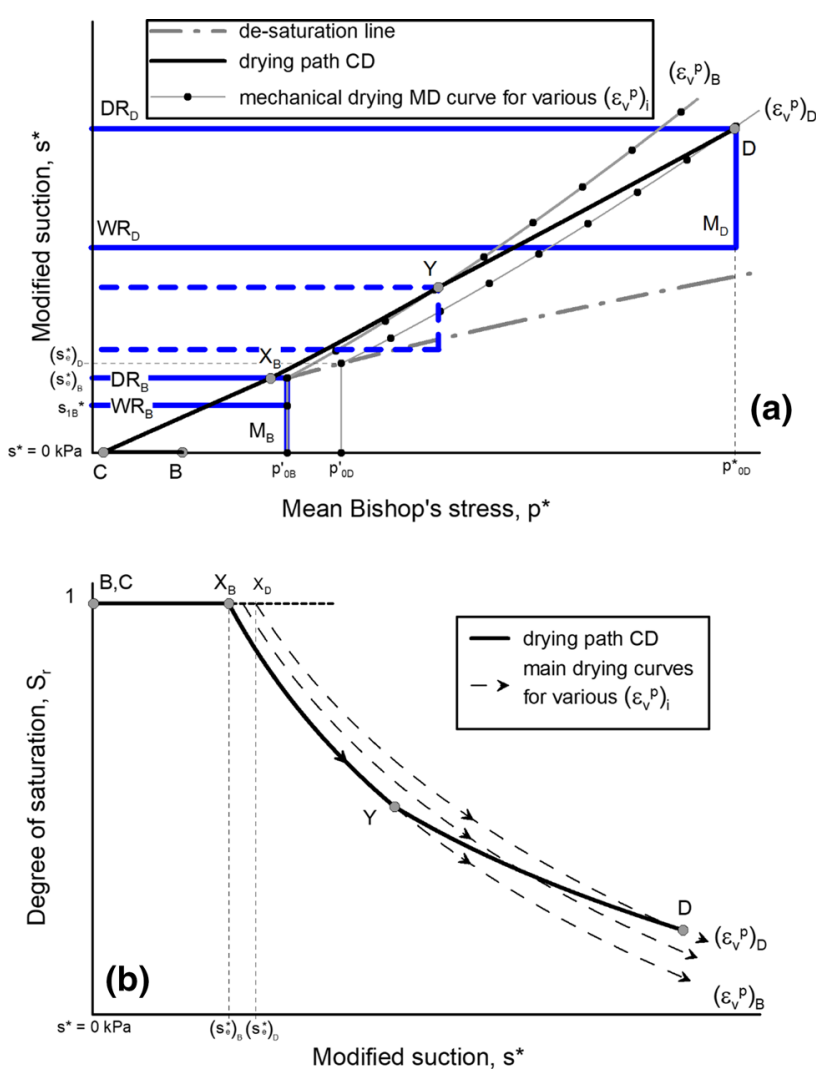

Fig. 5 Typical model response during a drying path at constant net stress: a stress path in the $s^{*}: p^{*}$ plane; $\mathbf{b}$ water retention behaviour 
positions of the three yield surfaces at this initial saturated configuration are still labelled by the subscript $\mathrm{B}$, because $\mathrm{BC}$ is purely elastic unloading (Fig. 5a).

In the simulations presented in Fig. 5, the soil remains saturated until point $X_{B}$ (the air-entry point), where the DR surface is reached (Fig. 5a) and de-saturation takes place (Fig. 5b). The air-entry point $\mathrm{X}_{\mathrm{B}}$ lies to the left of the desaturation line in Fig. 5a, because the soil is in an overconsolidated state (not on the M yield surface) at this point. The air-entry point does, however, correspond to a value of $s^{*}$ at which the MD curve (currently in a position labelled $\left(\varepsilon_{\mathrm{v}}^{\mathrm{p}}\right)_{\mathrm{B}}$ in Fig. 5a) intersects the de-saturation line.

From the air-entry point $\mathrm{X}_{\mathrm{B}}$ until $\mathrm{Y}$, plastic decreases in $S_{r}$ are caused by yielding on only the DR yield surface, and therefore, the evolution of $S_{r}$ in Fig. 5b follows a constant $\left(\varepsilon_{\mathrm{v}}^{\mathrm{p}}\right)$ main drying curve corresponding to the initial state of plastic volumetric strain $\left(\varepsilon_{\mathrm{v}}^{\mathrm{p}}\right)_{\mathrm{B}}$ (only elastic shrinkage is predicted from $\mathrm{X}_{\mathrm{B}}$ to $\mathrm{Y}$ ).

The mechanical yield surface is reached at $Y$, because the rightward movement of the stress point occurs faster than the coupled outward movement of the $M$ surface predicted during yielding on the DR surface alone. The locations of the three yield surfaces at point $\mathrm{Y}$ on the drying path are indicated by dashed lines in Fig. 5a. This yield point corresponds to the intersection of the stress path with the current MD curve (indicated by $\left(\varepsilon_{\mathrm{v}}^{\mathrm{p}}\right)_{\mathrm{B}}$ in Fig. 5a). Simultaneous yielding on $\mathrm{M}$ and DR yield surfaces is predicted from $\mathrm{Y}$ to $\mathrm{D}$, causing plastic volumetric compression (drying-induced plastic shrinkage) and plastic decreases in $S_{r}$. Equivalent to the discussion on the MW curve during collapse compression, the MD curve expands if plastic compression occurs on drying (see the increase in the saturated mechanical yield stress from $p_{0 \mathrm{~B}}^{\prime}$ to $p_{0 \mathrm{D}}^{\prime}$ in Fig. 5a).

In contrast to section $\mathrm{X}_{\mathrm{B}} \mathrm{Y}$, changes of $S_{r}$ beyond $\mathrm{Y}$ are no longer on the constant $\left(\varepsilon_{\mathrm{v}}^{\mathrm{p}}\right)$ main drying curve corresponding to $\left(\varepsilon_{\mathrm{v}}^{\mathrm{p}}\right)_{\mathrm{B}}$, because plastic volumetric strains are now predicted, in addition to the plastic decreases in $S_{r}$. The predicted retention behaviour from Y to D shows $S_{r}$ decreasing at a lower rate than would have been predicted in the absence of plastic shrinkage (Fig. 5b). The final positions of the three yield surfaces at the end of the drying are indicated in Fig. 5a by the subscript D.

\section{From full saturation to unsaturated conditions}

There are many experimental studies in the literature that examine the occurrence of de-saturation (air-entry point) from the evolution of degree of saturation against suction typically obtained during air-drying of reconstituted (initially saturated) soil samples under unconfined (or very low) stress conditions (e.g. $[18,21,57,69,75])$. To include, in such experimental investigations, the influence that dry density (or plastic volumetric strain) has on the airentry point, it is useful to conduct the same type of airdrying paths on several samples that have been previously pre-consolidated to different values of stress. On subsequent application of drying, the various saturated samples are expected to de-saturate at different air-entry values of suction because of the different initial stress histories. From these observations, the influence of dry density (or plastic volumetric strain) on de-saturation can be assessed.

\subsection{Simulations of air-drying tests on $\mathrm{OC}$ samples of Barcelona clayey silt [13]}

Boso [13] conducted a series of air-drying tests at a very low vertical stress on samples of reconstituted Barcelona clayey silt. This low-activity soil has $17 \%$ clay content and the following basic properties: liquid limit 32\%, plastic limit $16 \%$ and unit weight of solids $26.7 \mathrm{kN} / \mathrm{m}^{3}$ [13]. The reconstituted samples had mono-modal pore size distributions [13]. Each sample was initially one-dimensionally consolidated (under saturated conditions) to a vertical effective stress $\sigma_{\mathrm{v} 0}^{\prime}$ of 100,300 or $500 \mathrm{kPa}$, then unloaded to very low stress conditions and slightly reloaded to $14 \mathrm{kPa}$ to accommodate the sample into a monitored suction shear box with high-range tensiometers [16], before conducting the air-drying path [68]. Several samples were tested with each value of saturated vertical pre-consolidation stress $(100,300$ or $500 \mathrm{kPa})$, and the various samples within each group were finally air-dried to different values of suction.

The stress paths followed in these experimental tests are illustrated in Fig. 6. All stress paths start at the same saturated initial state A on the saturated 1D normal compression line (ncl). The initial very low stress is assumed equal to $1 \mathrm{kPa}$ in the simulations of the tests presented later. The specific volume at this point thus corresponds to the intercept $\bar{N}$ of the saturated 1D ncl because, at this stage, $s=0 \mathrm{kPa}$ and the vertical net stress $\bar{\sigma}_{\mathrm{v} 0}$, vertical saturated effective stress $\sigma_{\mathrm{v} 0}^{\prime}$ and vertical Bishop's stress $\sigma_{\mathrm{v} 0}^{*}$ all have a value of $1 \mathrm{kPa}$. An initial vertical consolidation was simulated first, from A to the appropriate vertical effective stress $\sigma_{\mathrm{v} 0}^{\prime}$ at B, C or D (Fig. 6). After unloading each sample to the very low stress conditions at $\mathrm{E}$, the simulations include a small reloading, as the vertical effective stress was increased from 1 to $14 \mathrm{kPa}$ (as indicated by EF in Fig. 6). An air-drying path was subsequently simulated (at a constant stress of $14 \mathrm{kPa}$ ) to the final value of $s$ at G (see Fig. 6). As expected, the different amounts of mechanical yielding experienced by the samples at B, C and D led to different values of suction at de- 


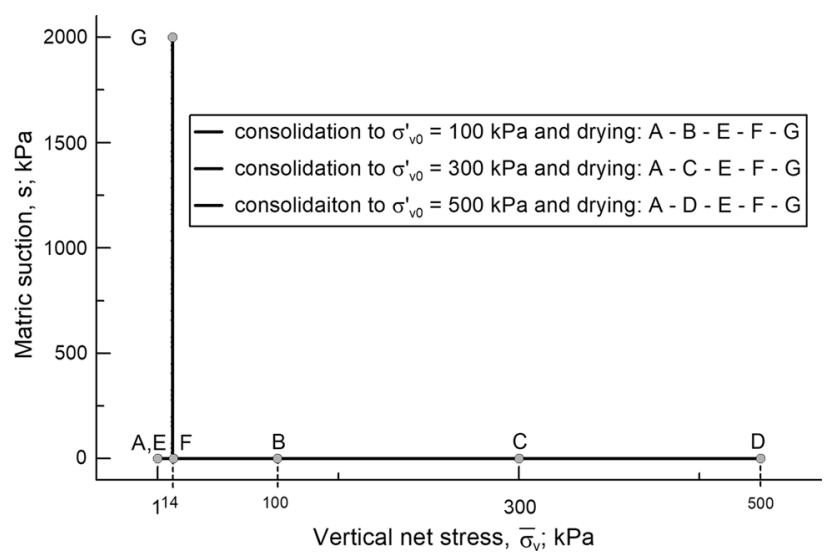

Fig. 6 Applied stress path for the experimental tests of Boso [13]

Table 1 Values of soil constants for the model simulations for Boso [13] tests

\begin{tabular}{llll}
\hline $\bar{\lambda}=0.084$ & $\bar{\kappa}=0.007$ & $\bar{N}=1.910$ & $R=1.400$ \\
$\bar{N}^{*}=1.962$ & $\bar{k}_{1}=0.372$ & $\bar{k}_{2}=0.750$ & $\lambda_{\mathrm{s}}=0.145$ \\
\hline
\end{tabular}

saturation (air-entry points) in both experiments and simulations.

The model parameter values used in the simulations are summarised in Table 1, where the upper bar indicates that they correspond to 1D loading (zero lateral strain), rather than isotropic loading. The intercept $\bar{N}$ and gradient $\bar{\lambda}$ of the saturated 1D ncl, together with the gradient $\bar{\kappa}$ of a 1D unloading-reloading line (url), were determined from a saturated oedometric test on a reconstituted sample of Barcelona clayey silt that had been previously vertically consolidated to $100 \mathrm{kPa}$ [13]. The simulation of this saturated test is presented in the $v: \ln \sigma_{\mathrm{v}}^{\prime}$ plane in Fig. 7, where the experimental results are indicated by symbols.

The gradient $\lambda_{\mathrm{s}}$ of the main drying curve in the $S_{r}: \ln s^{*}$ plane was estimated from the experimental evolution of $S_{r}$ observed during the initial stages of the drying paths presented in Fig. 8. In doing so, it was necessary to ensure that no plastic volumetric compression occurred during the section of retention response considered to estimate this gradient. This was a reasonable assumption for the first part of each drying path, because, as confirmed later, the high values of overconsolidation ratio OCR of all the reconstituted samples, immediately before drying, meant that the corresponding position of the $\mathrm{M}$ yield surface was far away from the current stress point and the decreases in $S_{r}$ during the initial stages of drying involved yielding on only the DR yield surface (with no plastic compression). Hence, the initial part of each test followed a constant $\left(\varepsilon_{\mathrm{v}}^{\mathrm{p}}\right)$ main drying curve.

The value of the soil constant $\bar{k}_{2}$ was determined by examining the air-entry values of modified suction $s_{e}^{*}$ for

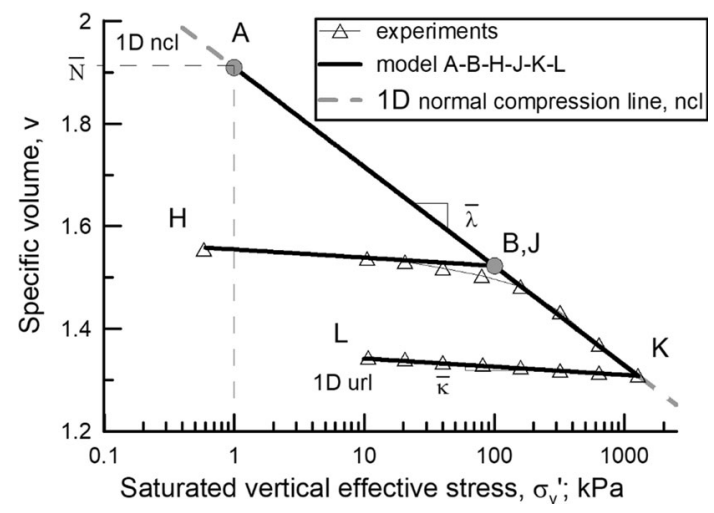

Fig. 7 Model predictions and experimental variations of a saturated oedometric test [13]

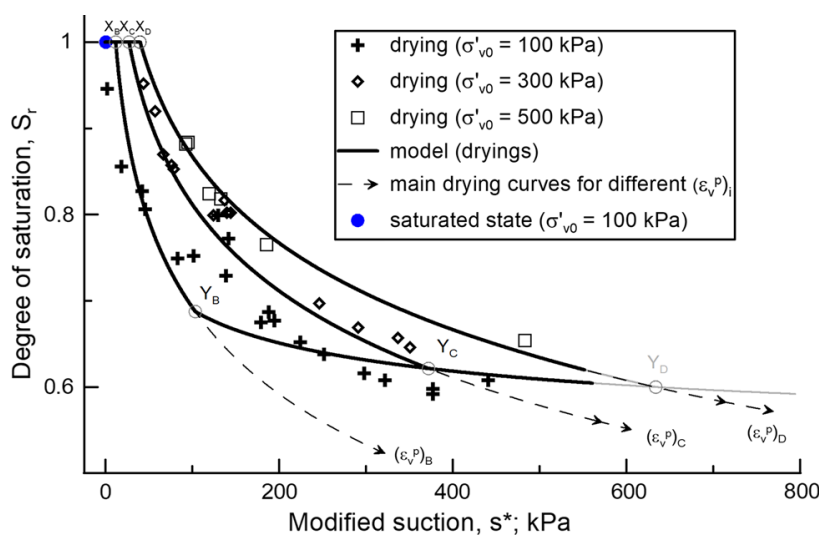

Fig. 8 Model predictions and experimental variations of $S_{r}$ against $s^{*}$ [13]

the three groups of tests corresponding to the three values of vertical pre-consolidation stress $(100,300$ and $500 \mathrm{kPa})$. The experimental value of $s_{e}^{*}$ for each value of vertical preconsolidation stress was first determined by best-fitting the experimental data for the early part of the drying retention curves for the appropriate group of tests by a straight line of gradient $\lambda_{\mathrm{s}}$ in the $S_{r}: \ln s^{*}$ plane (using the value of $\lambda_{\mathrm{s}}$ already determined) and then finding the intersection of this line with $S_{r}=1$. These three air-entry values $s_{\mathrm{e}}^{*}$ should be related to the vertical pre-consolidation stress $\sigma_{\mathrm{v} 0}^{\prime}$ through the equation of the de-saturation line (equivalent to Eq. 3, but with $p_{0}^{\prime}$ replaced by $\sigma_{\mathrm{v} 0}^{\prime}$, to reflect the $1 \mathrm{D}$ conditions). The three pairs of values of $s_{\mathrm{e}}^{*}$ and $\sigma_{\mathrm{v} 0}^{\prime}$ were plotted in the $\ln s_{\mathrm{e}}^{*}: \ln \sigma_{\mathrm{v} 0}^{\prime}$ plane and the gradient of the bestfit straight line through these points was used to determine the value of $\bar{k}_{2}$ (see Eq. 3).

The values of the three remaining soil constants $R, \bar{N}^{*}$ and $\bar{k}_{1}$ (see Appendix) were determined using an iterative procedure, intended to optimise the fit of the model simulations to the experimental variations of $v$ and $S_{r}$. This procedure made use of experimental data from the subsequent constant water content loading stages of Boso [13] 
(discussed in the next section) as well as the air-drying stages discussed in this section, because determination of a value for the model parameter $R$ requires experimental data involving yielding on both WR and DR yield surfaces.

Table 2 provides details of the common initial state (prior to the saturated pre-consolidation stage) used for all model simulations, corresponding to point $\mathrm{A}$ in Fig. 9, lying on the saturated 1D ncl (Fig. 7). Hence, the initial value of the mechanical hardening parameter (defining the initial position of the $\mathrm{M}$ surface) was $\sigma_{\mathrm{v} 0 \mathrm{~A}}^{\prime}=1 \mathrm{kPa}$. Inserting this value into Eq. 3 of the de-saturation line (together with the appropriate model parameter values, see Table 1) gave the corresponding air-entry value of modified suction at $\mathrm{A}$, which defines the initial position of the DR yield surface ( $s_{\mathrm{eA}}^{*}$ in Fig. 9). Although not used in the simulations presented in this section, the initial position of the WR yield surface was also determined using $s_{\mathrm{exA}}^{*}=s_{\mathrm{eA}}^{*} / R$, where $s_{\mathrm{exA}}^{*}$ is the air-exclusion at point A. The initial positions of the MW and MD curves introduced earlier, together with the saturation and de-saturation lines, are also included in Fig. 9 for completeness.

The experimental and simulated responses for the drying stress paths FG plotted in Fig. 6 are shown for the three different pre-consolidation stresses $(100,300$ and $500 \mathrm{kPa})$ in Figs. 10, 11 and 12, respectively. The results in each of the three figures are presented in four parts. Part (a) shows the variation of matric suction $s$ against vertical net stress $\bar{\sigma}_{\mathrm{v}}$ (the defined stress path, used as input for the simulations), whereas part (b) presents the variation of modified suction $s^{*}$ against vertical Bishop's stress $\sigma_{\mathrm{v}}^{*}$. Parts (c) and (d) show, respectively, the evolution of specific volume $v$

Table 2 Initial state for model simulations for Boso [13] tests

\begin{tabular}{llll}
\hline $\bar{\sigma}_{\mathrm{v}}=1.0 \mathrm{kPa}$ & $v=1.910$ & $\sigma_{\mathrm{v}}^{*}=1.0 \mathrm{kPa}$ & $\sigma_{\mathrm{v} 0}^{*}=1.0 \mathrm{kPa}$ \\
$s=0 \mathrm{kPa}$ & $S_{r}=1.0$ & $s_{1}^{*}=0.271 \mathrm{kPa}$ & $s_{2}^{*}=0.379 \mathrm{kPa}$ \\
\hline
\end{tabular}

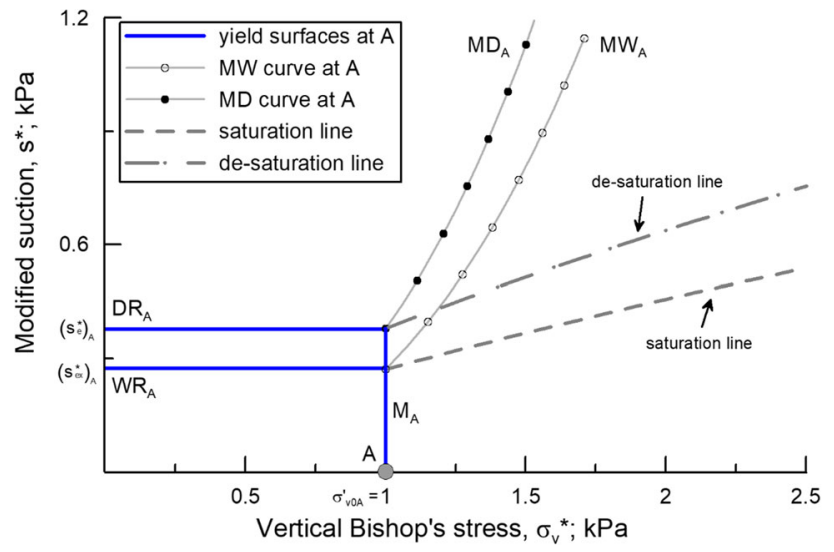

Fig. 9 Initial state for the simulations of the drying tests by Boso [13] in the context of the Glasgow Coupled Model (GCM)
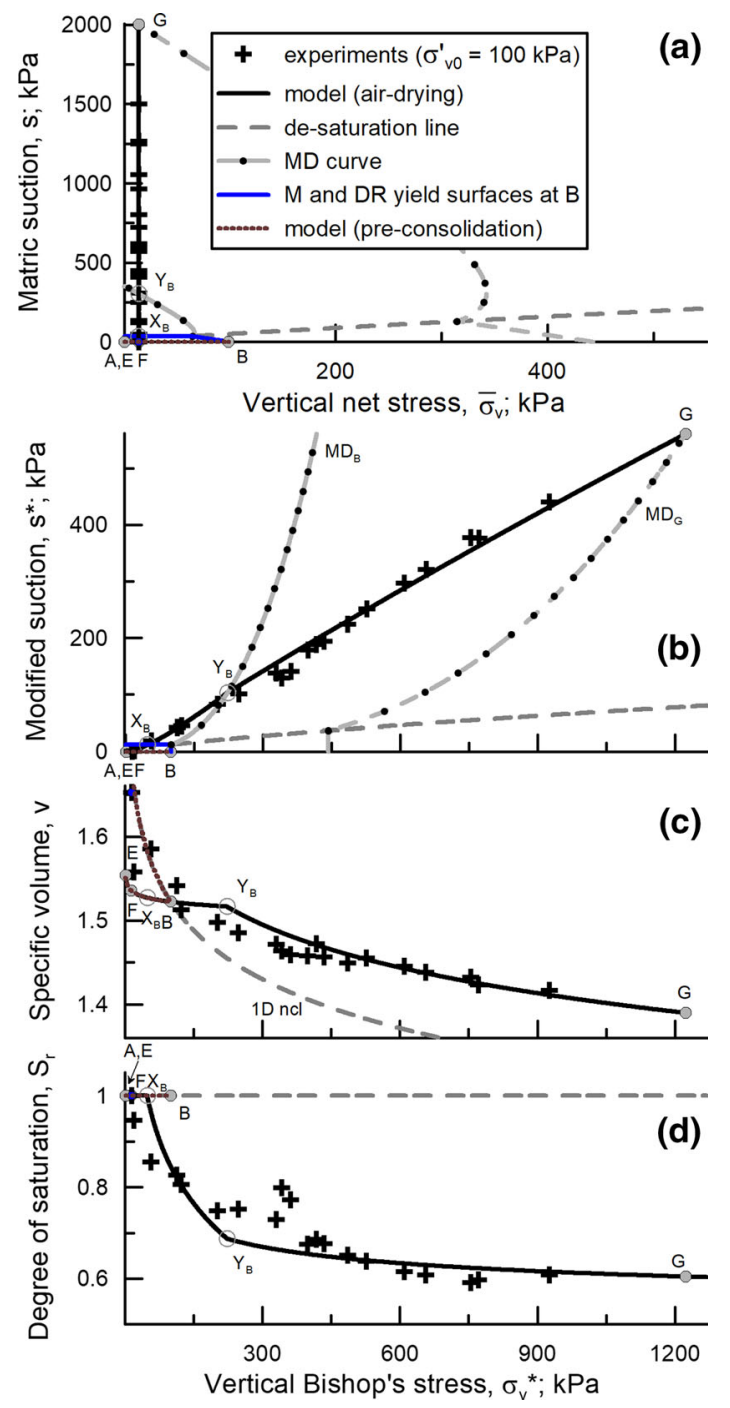

Fig. 10 Model predictions and experimental results of air-drying tests for samples vertically consolidated to $\sigma_{\mathrm{v} 0}^{\prime}=100 \mathrm{kPa}$ [13]: a $s$ against $\bar{\sigma}_{\mathrm{v}} ; \mathbf{b} s^{*}$ against $\sigma_{\mathrm{v}}^{*} ; \mathbf{c} v$ against $\sigma_{\mathrm{v}}^{*} ; \mathbf{d} S_{r}$ against $\sigma_{\mathrm{v}}^{*}$

and of degree of saturation $S_{r}$ against $\sigma_{\mathrm{v}}^{*}$. All three examples start at the same initial state A on the saturated ncl, as illustrated in Figs. 7 and 9 (see also Table 2). In Figs. 10, 11 and 12, the continuous thicker line represents the model response on drying, whereas the dotted thicker line corresponds to the model response for the initial pre-consolidation stage (still under saturated conditions). Continuous thinner lines indicate the position of the M and DR yield surfaces just before drying (Figs. 10a, b, 11a, b, 12a, b) (this is difficult to see in Fig. 10a, b, because the elastic region is so small in this case). Note that for clarity the position of the WR surface is not included in the plots. The de-saturation line is indicated by a thick dashed line (Figs. 10a, b, 11a, b, 12a, b), and the positions of the MD curve at initial and final points of the air-drying simulation 

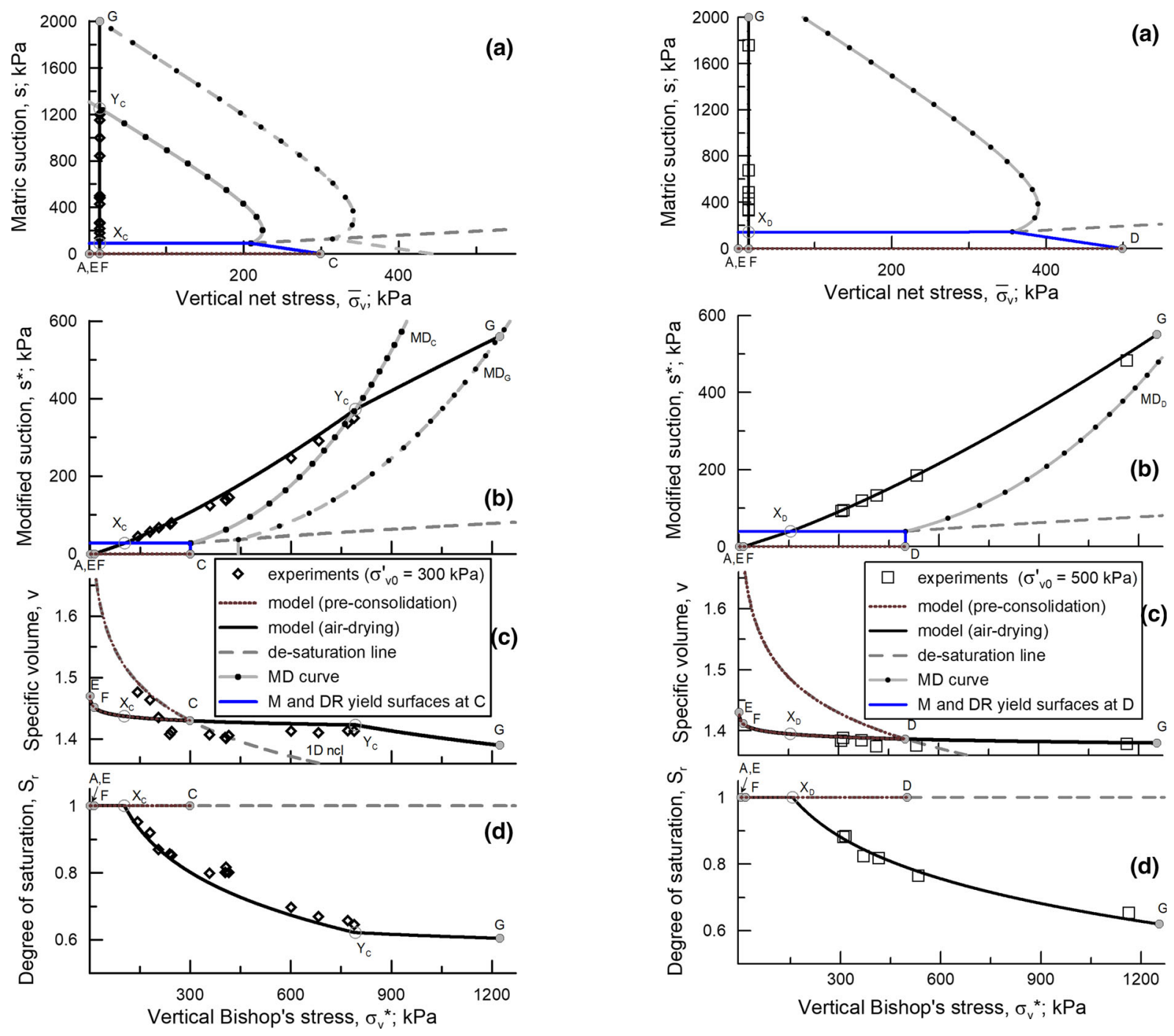

Fig. 11 Model predictions and experimental results of air-drying tests for samples vertically consolidated to $\sigma_{\mathrm{v} 0}^{\prime}=300 \mathrm{kPa}$ [13]: a $s$ against $\bar{\sigma}_{\mathrm{v}} ; \mathbf{b} s^{*}$ against $\sigma_{\mathrm{v}}^{*} ; \mathbf{c} v$ against $\sigma_{\mathrm{v}}^{*} ; \mathbf{d} S_{r}$ against $\sigma_{\mathrm{v}}^{*}$

are indicated by lines with plain symbols (Figs. 10a, b, 11a, $b, 12 a, b)$.

As expected, mechanical yielding occurs throughout the initial saturated pre-consolidation stage $\mathrm{AB}, \mathrm{AC}$ or $\mathrm{AD}$ (see Fig. 6) and the specific volume reduces, following the one dimensional saturated normal compression line (1D ncl), as illustrated in Figs. 10c, 11c and 12c. The occurrence of mechanical yielding on loading produces a coupled movement of the DR and WR surfaces to higher values of modified suction (increasing both air-entry and air-exclusion values of suction). The value of vertical Bishop's stress (identical to vertical effective stress for these saturated conditions) at $\mathrm{B}, \mathrm{C}$ or $\mathrm{D}$ defines the position of the $\mathrm{M}$ yield surface at the end of the pre-consolidation stage and also controls the positions of the DR and WR yield surfaces at this stage (Figs. 10b, 11b, 12b). During the subsequent

Fig. 12 Model predictions and experimental results of air-drying tests for samples vertically consolidated to $\sigma_{\mathrm{v} 0}^{\prime}=500 \mathrm{kPa}$ [13]: a $s$ against $\bar{\sigma}_{\mathrm{v}} ; \mathbf{b} s^{*}$ against $\sigma_{\mathrm{v}}^{*} ; \mathbf{c} v$ against $\sigma_{\mathrm{v}}^{*} ; \mathbf{d} S_{r}$ against $\sigma_{\mathrm{v}}^{*}$

elastic unloading and reloading paths applied just before drying (BEF, CEF or DEF; see Fig. 6) the positions of the three yield surfaces remain unchanged.

The increase in matric suction during the air-drying path (at constant vertical net stress) leads to increases in the vertical Bishop's stress and modified suction (see Eqs. 1 and 2 , respectively). The increase in $\sigma_{\mathrm{v}}^{*}$ during drying causes initial elastic compression in all three simulations. De-saturation then occurs where the DR yield surface is reached (see points $\mathrm{X}$ in Figs. 10a, b, 11a, b, 12a, b). Due to the different amounts of coupled movement of the DR yield surface at B, C or D (see Fig. 6), de-saturation is predicted at different values of modified suction in the three sets of tests. Not surprisingly, de-saturation occurs at higher values of modified suction (or matric suction) in the tests where greater mechanical yielding was experienced 
by the soil during the initial pre-consolidation (see Figs. 10a, b, 11a, b, 12a, b). This result is consistent with the experimental tests of Boso [13] and is in general agreement with the interpretation given by Tarantino [68].

The relatively high values of OCR at point $\mathrm{F}$ in all tests prevent the occurrence of mechanical yielding during the initial stage FX of drying, while the soil sample is still saturated (the saturated section of the MD curve at B, C or $\mathrm{D}$ is sufficiently far away from the stress point at $\mathrm{F}$, and is consistently further away the larger was the applied vertical pre-consolidation stress $\sigma_{\mathrm{v} 0}^{\prime}$, see Figs. $10 \mathrm{~b}, 11 \mathrm{~b}, 12 \mathrm{~b}$, respectively). The variations of $v$ during this initial stage of drying (when the soil is still saturated, up to point $X_{B}, X_{C}$ or $\mathrm{X}_{\mathrm{D}}$ ) follow an elastic unloading-reloading line in the $v: \sigma_{\mathrm{v}}^{*}$ plot (see Figs. 10c, 11c, 12c) because no mechanical yielding is predicted.

De-saturation occurs at $\mathrm{X}$, and from $\mathrm{X}$ to $\mathrm{Y}$, plastic decreases in $S_{r}$ are predicted as a consequence of yielding on only the DR surface. Note that, in all cases, the stress point is to the left of the de-saturation line at point $\mathrm{X}$ where de-saturation occurs (see Figs. 10b, 11b, 12b), because the soil is still in an overconsolidated state (not on the M yield surface) at this point (as discussed previously). The irreversible decrease in $\mathrm{S}_{r}$ predicted by the model after point $\mathrm{X}$ matches reasonably well the experimental data, although some scatter exists in the experimental data (Figs. 10d, 11d, 12d).

Immediately after de-saturation, the increases in $\sigma_{\mathrm{v}}^{*}$ cause only elastic shrinkage (Figs. 10c, 11c, 12c), because the model predicts yielding on only the DR yield surface (the $\mathrm{M}$ yield surface has not yet been reached). Consequently, the evolution of $S_{r}$ initially follows a constant $\left(\varepsilon_{\mathrm{v}}^{\mathrm{p}}\right)$ main drying curve when plotted in the $S_{r}: s^{*}$ plane, consistent with the earlier assumption adopted in the determination of $\lambda_{\mathrm{s}}$ (Fig. 8). The variation of $v$ during this elastic shrinkage still follows the elastic unloadingreloading line in the $v: \sigma_{\mathrm{v}}^{*}$ plot, but is now able to pass beyond the saturated 1D ncl, because the soil is in an unsaturated condition (see Figs. 10c, 11c, 12c).

For the two simulations in which the drying path was conducted on specimens that experienced lower amounts of mechanical yielding during the pre-consolidation stage (Figs. 10c, 11c), the stress path reaches the current MD curve at $\mathrm{Y}$ (see Figs. 10b, 11b). This corresponds to reaching the $\mathrm{M}$ yield surface, and simultaneous plastic compression and plastic decreases in $S_{r}$ are therefore predicted for the remainder of the drying stage. The discontinuity of gradient in the predicted response of $S_{r}$ at $\mathrm{Y}$ (Figs. 10d, 11d) corresponds to this intersection and is consistent with previous comments on the influence of plastic compression on a main drying curve. This particular aspect of the predicted retention behaviour is illustrated more clearly in Fig. 8, where it can be seen that the simulations for the two drying paths conducted with lower preconsolidation stresses converge at $\mathrm{Y}_{\mathrm{C}}$. Interestingly, this pattern of behaviour on drying would also have been observed beyond point $Y_{D}$ for the final simulation (with the highest pre-consolidation stress) if the simulations for all dryings had been extended further (see Fig. 8). This is consistent with a number of experimental studies on retention behaviour available in the literature. In particular, Jotisankasa [34] and Jotisankasa et al. [35] observed a similar response when investigating various drying paths on a compacted silty clay for three different as-compacted states. On drying, the two tests subjected to lower compaction stresses converged first (i.e. at a lower value of suction), and all three converged later at a larger value of suction.

For the simulation of the tests performed with the highest value of pre-consolidation stress (see Fig. 12), the increase in suction during the air-drying path was not sufficient to reach the $\mathrm{M}$ yield surface (or, equivalently, the current position of the MD curve at D), as shown in Fig. 12b. Consequently, only elastic shrinkage was predicted throughout the drying (Fig. 12c), consistent with the variation of $S_{r}$ on a constant $\left(\varepsilon_{\mathrm{v}}^{\mathrm{p}}\right)$ main drying curve (see Fig. 8).

\subsection{Simulations of air-drying tests on NC and lightly OC samples}

All the air-drying tests of Boso [13] discussed above were performed on samples that were in a heavily overconsolidated state at the start of drying (OCR $=7.1,21.4$ or 35.7), with the initial stress state far inside the $M$ yield surface. As a consequence, in all of the GCM simulations of Boso's tests presented in Figs. 8, 9, 10, 11, and 12, the drying stress path reached the DR yield surface first, where the soil de-saturated, and only subsequently was the $M$ yield surface reached. However, this will not always be the case, and for drying tests on samples that are normally consolidated or lightly overconsolidated at the start of drying, the DR and M yield surfaces will be reached in a different sequence. Examples of such drying tests on normally consolidated or lightly overconsolidated reconstituted soil samples include those reported by Vicol [75], Fleureau et al. [21] and Cunningham [17].

Figures 13 and 14 show GCM simulations of drying tests performed on a normally consolidated sample (Fig. 13) and a lightly overconsolidated sample (Fig. 14). The labelling in Figs. 13 and 14 follows the same system as used in Figs. 8, 9, 10, 11, and 12, with F representing the start of the drying stage, $\mathrm{X}$ the point of de-saturation (airentry point) on the DR yield surface, $\mathrm{Y}$ the point of 

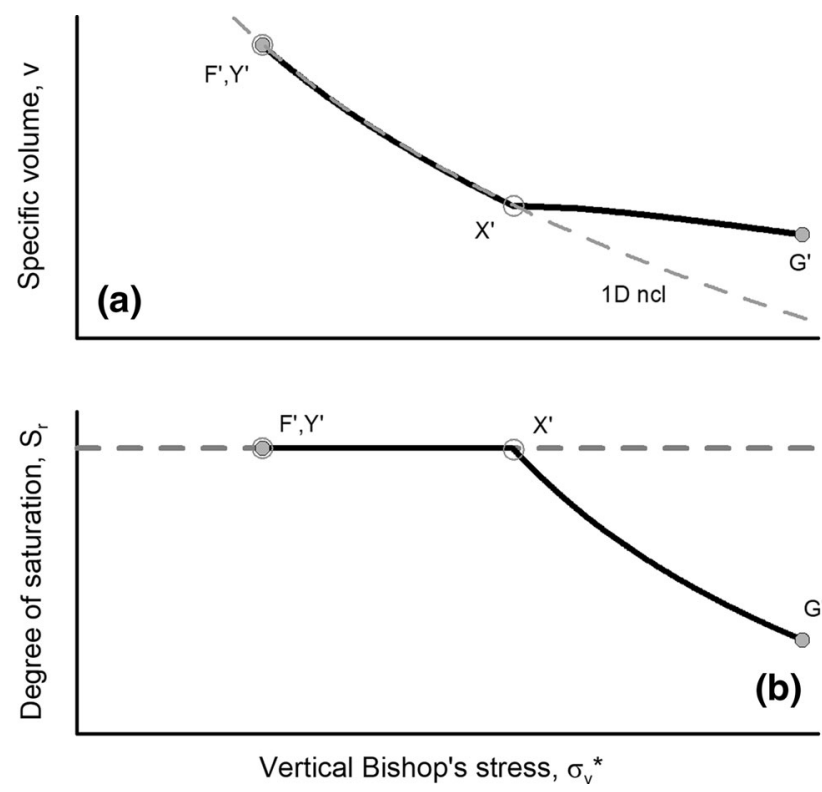

Fig. 13 Model predictions for air-drying tests on normal consolidated NC samples: a $v$ against $\sigma_{\mathrm{v}}^{*} ; \mathbf{b} S_{r}$ against $\sigma_{\mathrm{v}}^{*}$
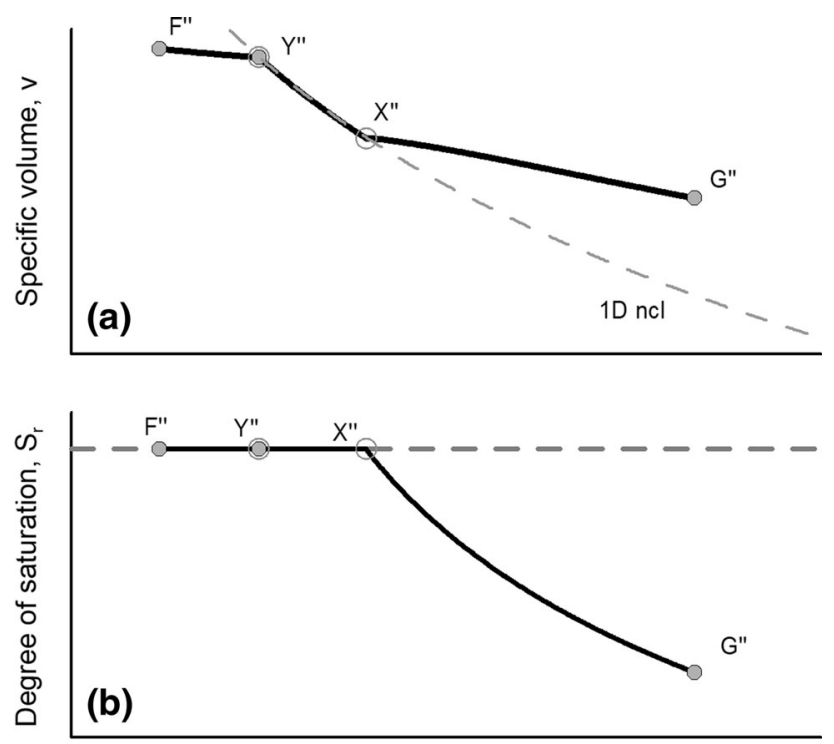

Vertical Bishop's stress, $\sigma_{\mathrm{v}}{ }^{*}$

Fig. 14 Model predictions for air-drying tests on lightly overconsolidated OC samples: a $v$ against $\sigma_{\mathrm{v}}^{*} ; \mathbf{b} S_{r}$ against $\sigma_{\mathrm{v}}^{*}$

yielding on the $\mathrm{M}$ yield surface (onset of plastic shrinkage) and $\mathrm{G}$ the end of the drying stage. Also shown by a dashed line in Figs. 13a and 14a is the saturated 1D normal compression line (1D ncl).

For the normally consolidated sample shown in Fig. 13, mechanical yielding on the $\mathrm{M}$ surface occurs from the start of drying $\left(\mathrm{Y}^{\prime}\right.$ coincides with $\left.\mathrm{F}^{\prime}\right)$ and de-saturation on the DR yield surface only occurs later, at $\mathrm{X}^{\prime}$ (see Fig. 13b). Between $\mathrm{F}^{\prime}$ and $\mathrm{X}^{\prime}$, the compression curve in Fig. 13a follows the saturated 1D ncl. For the lightly overconsolidated sample shown in Fig. 14, mechanical yielding on the $\mathrm{M}$ surface occurs at $\mathrm{Y}^{\prime \prime}$, while the soil is still saturated, and de-saturation on the DR yield surface occurs later at $\mathrm{X}^{\prime \prime}$. Between $\mathrm{F}^{\prime \prime}$ and $\mathrm{Y}^{\prime \prime}$, the compression curve in Fig. 14a follows an elastic unloading-reloading line (url), and between $Y^{\prime \prime}$ and $X^{\prime \prime}$, it follows the saturated 1D ncl. The GCM predictions shown in Figs. 13a and 14a are consistent with expected shrinkage behaviour for drying tests on normally consolidated or lightly overconsolidated reconstituted soil samples (e.g. [15, 70]) and match well the experimental behaviour reported by Vicol [75], Fleureau et al. [21], Marinho [42], Cunningham et al. [18], Tarantino et al. [69] and Al Haj and Standing [1].

\section{From unsaturated conditions to full saturation}

This section investigates the progressive increase in degree of saturation during loading and wetting paths, including final transition from unsaturated conditions to full saturation. Three different sets of experimental data are examined: constant water content loading tests on reconstituted Barcelona clayey silt [13]; wetting and isotropic loading tests on compacted Speswhite kaolin [63]; and constant volume wetting tests on compacted London clay [45].

A point to bear in mind when considering experimental data involving wetting to high degrees of saturation and transitions from unsaturated to saturated conditions is that model predictions assume achievement of equilibrium states within the soil, with full dissipation of any excess pore water pressure and excess pore air pressure. When the soil is at very high degree of saturation, with no continuity of the gas phase, full dissipation of any excess pore air pressure will take considerable time, because the only mechanism for dissipation of excess pore air pressure is by diffusion of dissolved air, which is a very slow process. This means that, unless experimental tests at high degrees of saturation are performed extremely slowly, the pore air pressure within discontinuous (trapped) air in the soil will not be equal to the pore air pressure applied to the boundary of a soil sample. As a consequence of the presence of undissipated excess pore air pressure, values of degree of saturation may be lower than if full dissipation had occurred.

\subsection{Simulations of constant water content loading tests on Barcelona clayey silt [13]}

Some of the air-dried samples of Boso [13] discussed in the previous section were vertically loaded under constant water content conditions (i.e. $\mathrm{d} w=0$ ) after application of the air-drying paths. For a group of samples with the same 
value of vertical pre-consolidation stress $\sigma_{\mathrm{v} 0}^{\prime}$ prior to drying, the drying stages were terminated at different values of suction, so that individual samples began their subsequent constant water content loading stages at different values of $s$. During the constant water content loading stages, the vertical net stress was increased in steps from 14 to 50 , 100, 200, 300, 400 and $500 \mathrm{kPa}$, although some tests did not include the final load increments [13, 68].

Figures 15, 16 and 17 present the experimental and numerical results of nine of the constant water content loading tests, to assess the capability of the GCM, including the validity of the saturation line. The values of GCM model parameters used in the simulations are given in Table 1 (i.e. the values determined from the previous air-drying stages). In Figs. 15, 16 and 17, the experimental data are indicated by thicker symbols joined by continuous lines (the solid symbols indicate experimental data at full saturation). For completeness, the experimental observations for the air-drying paths discussed previously in
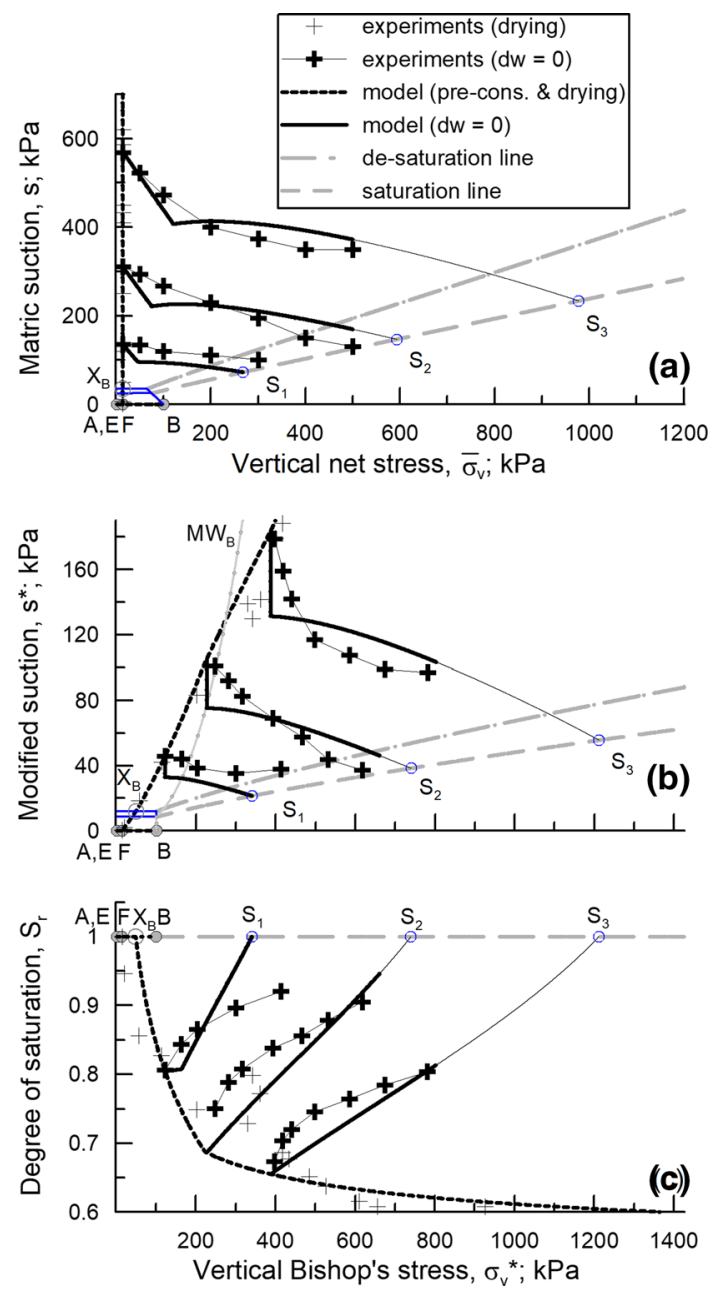

Fig. 15 Model predictions and experimental results of undrained loading tests for samples vertically consolidated to $\sigma_{\mathrm{v} 0}^{\prime}=100 \mathrm{kPa}$ [13]: a $s$ against $\bar{\sigma}_{\mathrm{v}} ; \mathbf{b} s^{*}$ against $\sigma_{\mathrm{v}}^{*} ; \mathbf{c} S_{r}$ against $\sigma_{\mathrm{v}}^{*}$
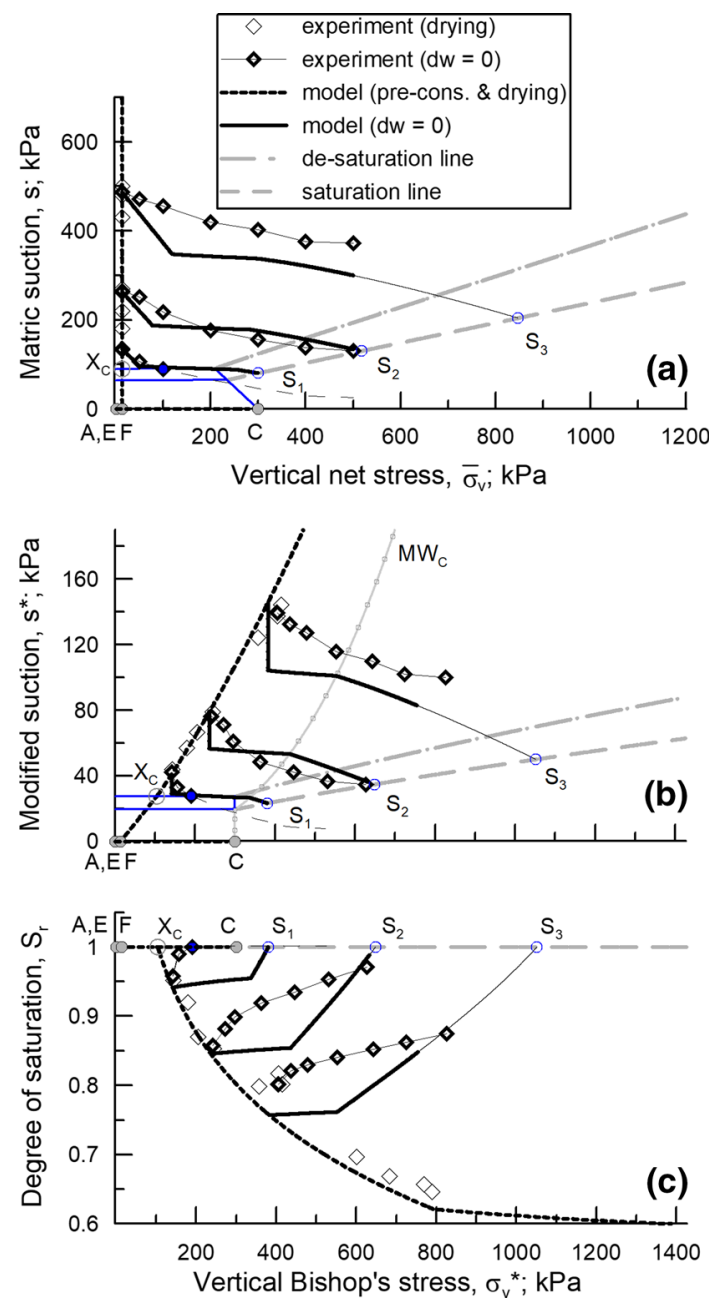

Fig. 16 Model predictions and experimental results of undrained loading tests for samples vertically consolidated to $\sigma_{\mathrm{v} 0}^{\prime}=300 \mathrm{kPa}$ [13]: a $s$ against $\bar{\sigma}_{\mathrm{v}} ; \mathbf{b} s^{*}$ against $\sigma_{\mathrm{v}}^{*} ; \mathbf{c} S_{r}$ against $\sigma_{\mathrm{v}}^{*}$

Figs. 10, 11 and 12 are also included (shown by finer symbols). The predicted saturation line is indicated by a dashed line whereas the predicted de-saturation line is indicated by a chain-dotted line. The positions of the three yield surfaces at the end of the pre-consolidation stage (B, $\mathrm{C}$ or D; see Fig. 6) have also been included in the appropriate figure together with the corresponding MW curve at $\mathrm{B}, \mathrm{C}$ or $\mathrm{D}$, respectively. The simulations for the experimental drying tests are indicated by thicker dashed lines and the simulations of the constant water content loading tests are indicated by thicker continuous lines. Note that, where necessary, the numerical simulations have been extended beyond the limit of experimental loading to investigate when the GCM would predict full saturation. These final parts of the simulations are represented in the figures by thinner continuous lines. The simulations of the loading tests at constant water content only required input information on the variation of vertical net stress, because the constraint $\mathrm{d} w=0$ imposed in the constitutive 

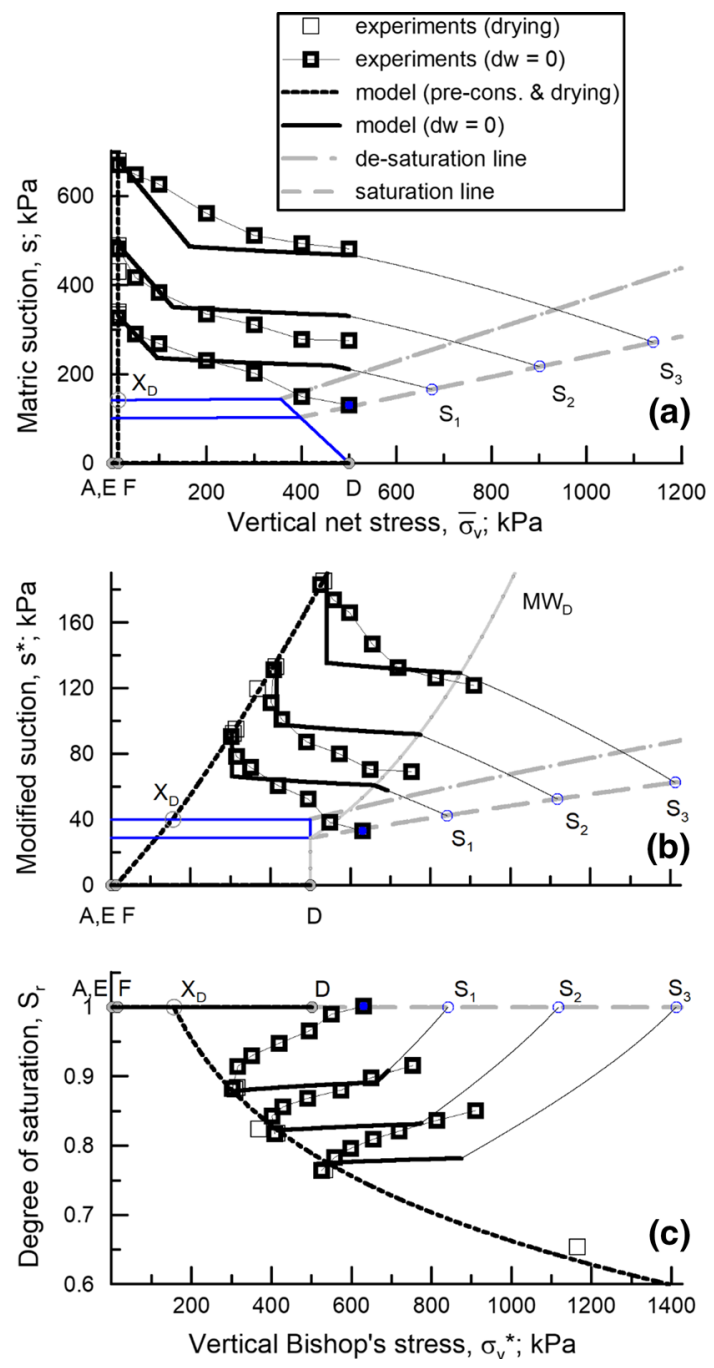

Fig. 17 Model predictions and experimental results of undrained loading tests for samples vertically consolidated to $\sigma_{\mathrm{v} 0}^{\prime}=500 \mathrm{kPa}$ [13]: a $s$ against $\bar{\sigma}_{\mathrm{v}} ; \mathbf{b} s^{*}$ against $\sigma_{\mathrm{v}}^{*} ; \mathbf{c} S_{r}$ against $\sigma_{\mathrm{v}}^{*}$

relationships of the GCM determines the variations of matric suction required to maintain the water content constant during the $1 \mathrm{D}$ loading.

Figure 15 shows the results of the constant water content loading stages on three samples with an initial vertical pre-consolidation stress $\sigma_{\mathrm{v} 0}^{\prime}$ of $100 \mathrm{kPa}$. For the simulation of the constant water content loading stage starting at the lowest value of suction, the start of the loading stage is on the DR yield surface but inside the $M$ yield surface. For this test, the initial vertical section of simulated stress path in the $s^{*}: \sigma_{\mathrm{v}}^{*}$ plane of Fig. 15b (corresponding to the steep initial section of stress path in the $s: \bar{\sigma}_{\mathrm{v}}$ plane of Fig. 15a) represents an elastic stress path from the DR yield surface to the WR yield surface, while still inside the $M$ yield surface. This part of the simulated stress path corresponds to a single point in the $S_{r}: \sigma_{\mathrm{v}}^{*}$ plane of Fig. $15 \mathrm{c}$, because both $S_{r}$ and $\sigma_{\mathrm{v}}^{*}$ remain constant. For this test, the sharp discontinuity of stress path gradient in the $s^{*}: \sigma_{\mathrm{v}}^{*}$ and $s: \bar{\sigma}_{\mathrm{v}}$ planes represents the point where the WR yield surface is reached. This is followed by a short almost horizontal section of stress path in the $s^{*}: \sigma_{\mathrm{v}}^{*}$ plane of Fig. $15 \mathrm{~b}$, where a very small amount of yielding on the WR yield surface is predicted, leading to very small plastic increases in $S_{r}$. This corresponds to the short almost horizontal section of path in the is $S_{r}: \sigma_{\mathrm{v}}^{*}$ plane of Fig. 15c. The subsequent sharp discontinuity of response in the $S_{r}: \sigma_{\mathrm{v}}^{*}$ plane of Fig. $15 \mathrm{c}$ corresponds to reaching the $M$ yield surface (as shown by the intersection with the $\mathrm{MW}_{\mathrm{B}}$ curve in Fig. 15b and the slight discontinuity of gradient in this plot). In the remainder of the simulated loading path, simultaneous yielding on both WR and M surfaces is predicted, leading to large plastic increases in $S_{r}$ (see Fig. 15c). Full saturation is predicted at $S_{1}$ (Fig. 15c), which corresponds to intersection of the stress path with the saturation line in Fig. 15a, b, whereas the experimental results show a final degree of saturation less than one (although above 0.9; see Fig. 15c).

For the simulation of the constant water content loading stage starting at an intermediate value of suction in Fig. 15, the stress state at the start of the loading stage is predicted to be on the DR yield surface and almost on the $\mathrm{M}$ yield surface. In this case, yielding on the WR surface (indicated by the sharp discontinuity of stress path gradient in Figs. 15a, b) almost coincides with yielding on the $\mathrm{M}$ yield surface (indicated by intersection of the stress path with the $\mathrm{MW}_{\mathrm{B}}$ curve in Fig. 15b and the onset of large plastic increases in $S_{r}$ in Fig. 15c). The simulation correctly predicts that full saturation did not occur during the loading stage, and it predicts that full saturation would have been achieved if the loading had been continued further to point $\mathrm{S}_{2}$ in Fig. 15a-c.

For the simulation of the constant water content loading stage starting at the highest suction in Fig. 15, the stress state at the start of loading is predicted to be on both DR and M yield surfaces. The initial vertical section of stress path in the $s^{*}: \sigma_{\mathrm{v}}^{*}$ plane of Fig. $15 \mathrm{~b}$ is simply traversing the M yield surface (without any occurrence of plastic volumetric strain) and the sharp discontinuity of stress path gradient in Figs. $15 \mathrm{a}, \mathrm{b}$ corresponds to reaching the WR yield surface. From this point onwards, simultaneous yielding on both $\mathrm{M}$ and WR yield surfaces is predicted, leading to a prediction of large plastic increases in $S_{r}$ (Fig. 15c). The simulation again correctly predicts that full saturation did not occur during the loading stage, and it predicts that full saturation would have been achieved if the loading had been continued further to point $S_{3}$ in Fig. 15a-c.

The simulations presented for all three constant water content loading stages in Fig. 15 show reasonable matches 
to the corresponding experimental results, especially when it is appreciated that the experimental data from the constant water content loading stages were not used in the selection of values for the model parameters (except for the value of the soil constant $R$ ).

Figures 16 and 17 show the results of the constant water content loading stages on samples with initial vertical preconsolidation stress $\sigma_{\mathrm{v} 0}^{\prime}$ of 300 and $500 \mathrm{kPa}$, respectively. In all six of the tests presented in these two figures, the predictions show stress states at the start of constant water content loading that are on the DR yield surface but well inside the $M$ yield surface. In all six cases, this leads to predicted responses where yielding on the WR yield surface is predicted first (indicated by the sharp discontinuity of stress path gradient in Figs. 16a, b, 17a, b), and this is subsequently followed by yielding on the $\mathrm{M}$ yield surface (indicated by the subtle discontinuity of stress path gradient in Figs. 16a, b and 17a, b, the intersection with the MW curve in Figs. 16b and 17b, and the sharp discontinuity of gradient in the $S_{r}: \sigma_{\mathrm{v}}^{*}$ plane of Figs. $16 \mathrm{c}$ and $17 \mathrm{c}$ ). In two of the tests in Fig. 17, this predicted onset of yielding on the $M$ yield surface almost coincides with the end of the loading stage, but it is apparent in the extended predictions shown by the thinner continuous lines.

\subsection{Simulations of isotropic loading and wetting tests on compacted Speswhite kaolin [63]}

The experimental isotropic compression tests of Sivakumar [63] on compacted Speswhite kaolin were simulated with the GCM in Lloret-Cabot et al. [41] to validate some of the capabilities of the model for isotropic stress conditions. However, none of the isotropic loading tests conducted at constant nonzero suction reported by Sivakumar [63] reached full saturation and neither did the corresponding GCM simulations presented in [41]. To discuss how the GCM handles achievement of full saturation during compression paths at constant suction, it is useful to extend these simulations to reach $S_{r}=1$, as presented in the following. The representation of full saturation during wetting can be also studied from the simulations of the equalisation stages of the tests involving wetting to $s=0$ prior to isotropic loading. The basic properties of this low-activity kaolin are: liquid limit $69 \%$, plastic limit $38 \%$ and unit weight of solids $26.1 \mathrm{kN} / \mathrm{m}^{3}$ [23].

The stress paths of the simulations are presented in Fig. 18. They all start at the same initial state A on the WR yield surface (and inside the $\mathrm{M}$ yield surface), corresponding to a matric suction of $300 \mathrm{kPa}$ and a mean net stress of $50 \mathrm{kPa}$. Initial wetting (equalisation) stress paths for different groups of samples are shown by the dashed lines $\mathrm{AB}, \mathrm{AC}$ and $\mathrm{ADEF}$ in Fig. 18, whereas subsequent

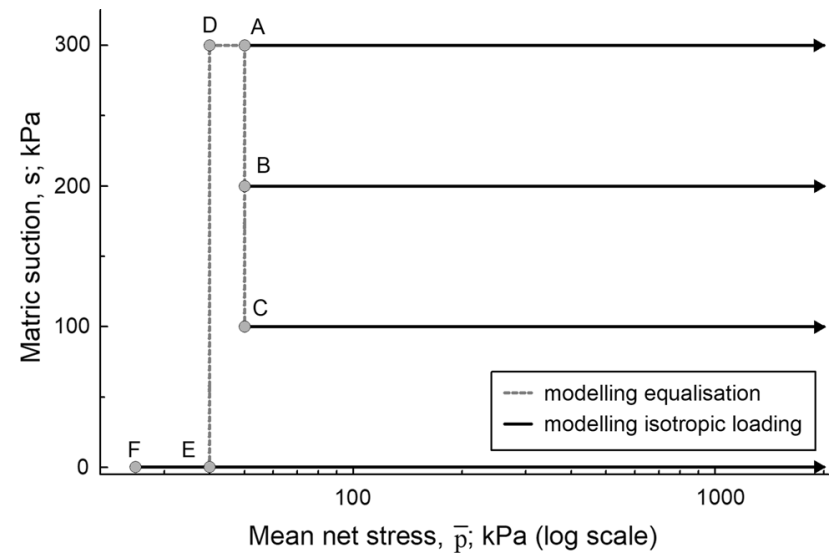

Fig. 18 Applied stress path for the experimental tests of Sivakumar [63]

Table 4 Initial state for model simulations for Sivakumar [63] tests [41]

\begin{tabular}{llll}
\hline $\bar{p}=50 \mathrm{kPa}$ & $v=2.210$ & $p^{*}=218.5 \mathrm{kPa}$ & $p_{0}^{*}=267.9 \mathrm{kPa}$ \\
$s=300 \mathrm{kPa}$ & $S_{r}=0.562$ & $s^{*}=164.3 \mathrm{kPa}$ & $s_{1}^{*}=164.3 \mathrm{kPa}$ \\
\hline
\end{tabular}

Table 3 Values of soil constants for the model simulations for Sivakumar [63] tests [41]

\begin{tabular}{llll}
\hline$\lambda=0.123$ & $\kappa=0.010$ & $N=2.621$ & \\
$N^{*}=2.728$ & $k_{1}=0.715$ & $k_{2}=0.737$ & $\lambda_{\mathrm{s}}=0.129$ \\
\hline
\end{tabular}

constant suction isotropic loading stages are shown by the continuous lines starting from A, B, C and F. In order to reach full saturation during simulations of all isotropic loading stages conducted at nonzero suction (starting at A, $\mathrm{B}$ and $\mathrm{C}$ ), a maximum final value of mean net stress of $2000 \mathrm{kPa}$ was assumed in all simulations, whereas the experiments were terminated at lower values of mean net stress. The values of model parameters (soil constants and initial state) used for the simulations were the same as those determined in [41] (see Tables 3, 4). In all subsequent figures, model simulations of the equalisation stages are indicated by thick dashed lines whereas simulations of constant suction isotropic loading stages are indicated by thick solid lines. Experimental data are represented by symbols joined by thin solid lines.

Figure 19 shows the experimental evolution of degree of saturation against matric suction (Fig. 19a) and against mean Bishop's stress (Fig. 19b). In the GCM simulations, tests reach full saturation (i.e. $S_{r}=1$ ) at different values of (nonzero) matric suction either during constant suction loading (see points $S_{1}, S_{2}$ and $S_{3}$ in Fig. 19) or during the prior wetting (equalisation) stage of the tests involving loading at $s=0$ (see point $S_{4}$ in Fig. 19). These values of $s$ at $\mathrm{S}_{1}, \mathrm{~S}_{2}, \mathrm{~S}_{3}$ and $\mathrm{S}_{4}$ define the air-exclusion point for each 

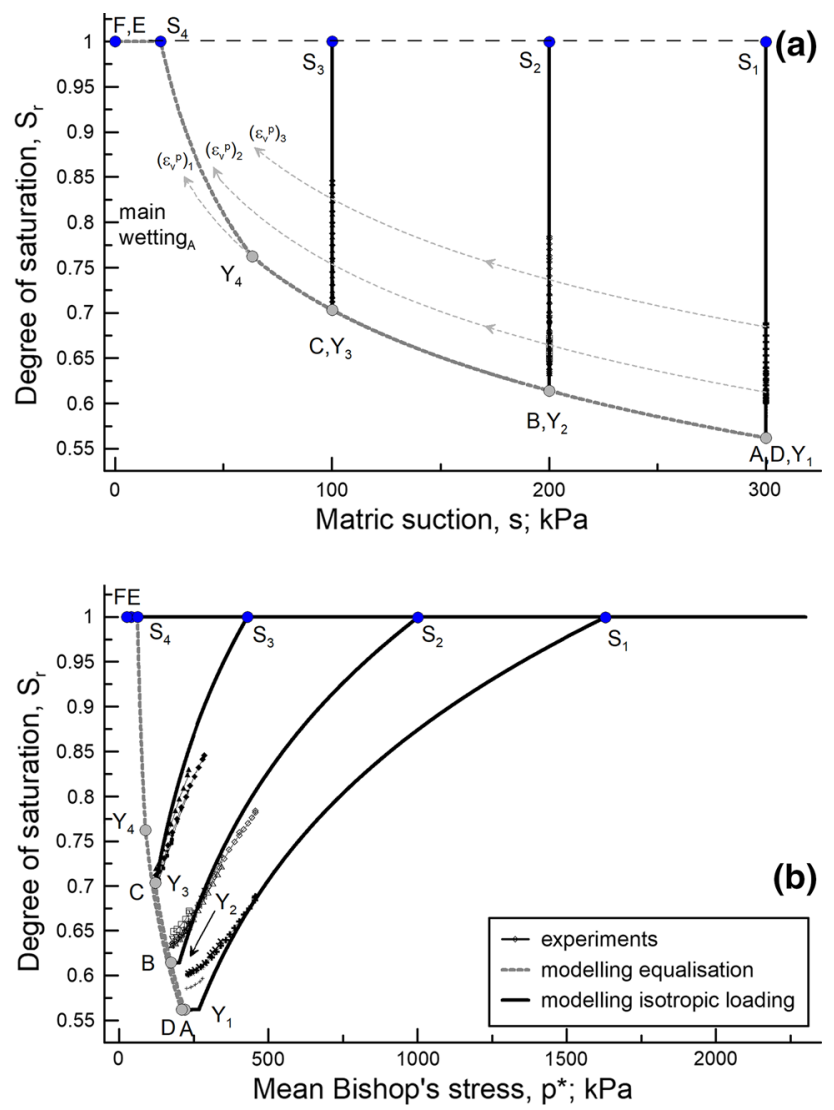

Fig. 19 Model predictions and experimental variations of $S_{r}$ [63]: a against $s$; b against $p^{*}$

test. The corresponding values of mean Bishop's stress $p^{*}$ at saturation (see points $S_{1}, S_{2}, S_{3}$ and $S_{4}$ in Fig. 19b) are equal to the saturated mean effective stress $p^{\prime}$ because $S_{r}=1$ and define the mechanical yield stress at saturation $p_{0}^{\prime}$ for each test because, as demonstrated in Fig. 20, mechanical yielding is predicted in all cases before reaching $S_{r}=1$, so that the stress point at saturation is on the $\mathrm{M}$ yield surface (as well as the WR yield surface). The values of mechanical yield stress at saturation $p_{0}^{\prime}$ in each test are predicted to increase with increasing air-exclusion values of suction, in correspondence with the form of the saturation line (see Eq. 4; Fig. 3).

Closer inspection of Fig. 19 shows that the predicted evolution of $S_{r}$ during the wetting (equalisation) stage DE has a slight increase in gradient beyond $\mathrm{Y}_{4}$. This discontinuity of gradient indicates the point where the $\mathrm{M}$ yield surface is reached and, hence, it also indicates the start of mechanical yielding. To illustrate more clearly the magnitude of this change in the water retention response, other constant $\left(\varepsilon_{\mathrm{v}}^{\mathrm{p}}\right)$ main wetting curves for different values of $\left(\varepsilon_{\mathrm{v}}^{\mathrm{p}}\right)_{i}$ are included in the figure (see thinner dashed lines in Fig. 19a). In particular, the main wetting curve corresponding to the initial position of the mechanical yield surface at $\mathrm{A}$ (labelled in the figure as $\left.\left(\varepsilon_{\mathrm{v}}^{\mathrm{p}}\right)_{1}\right)$ shows the
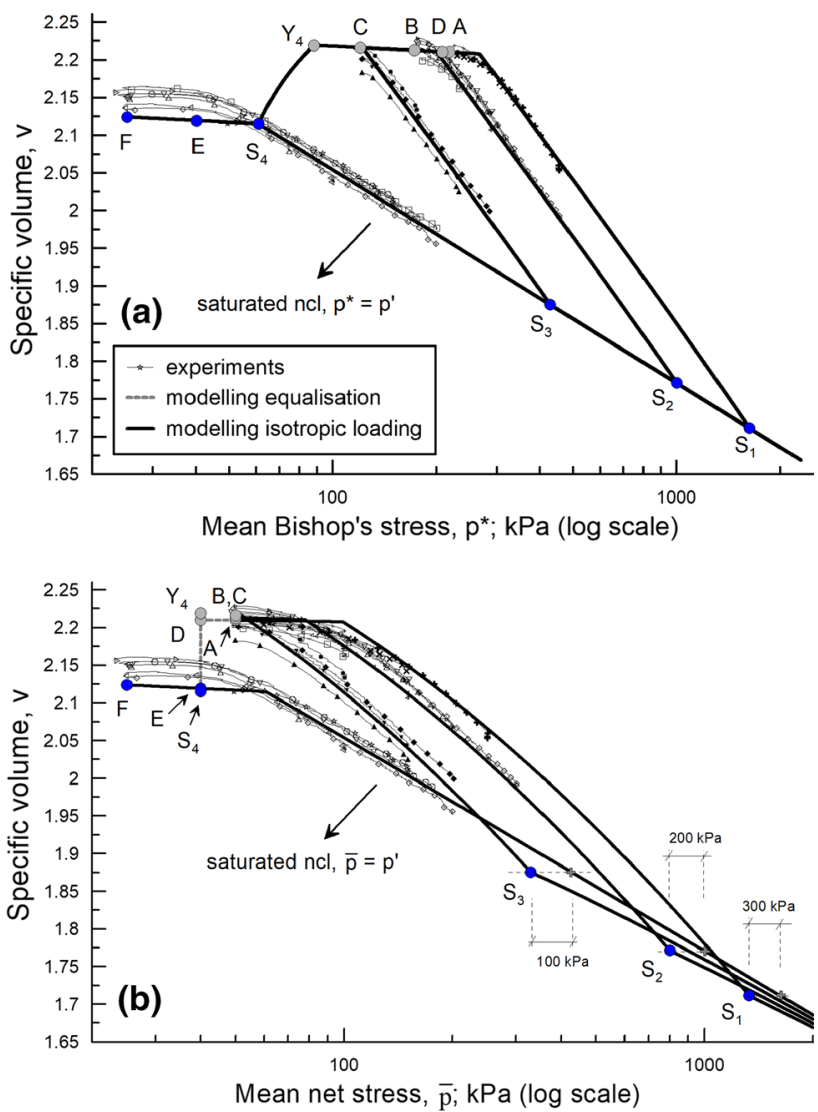

Fig. 20 Model predictions and experimental variations of $v$ [63]: a against $p^{*} ; \mathbf{b}$ against $\bar{p}$

retention response on wetting that would have been predicted if no yielding on the $\mathrm{M}$ surface had occurred, in support of earlier comments on the influence of collapse compression on the retention response during wetting.

Figure 20 plots the variations of specific volume $v$ against mean Bishop's stress $p^{*}$ (Fig. 20a) and against mean net stress $\bar{p}$ (Fig. 20b). As reported in Lloret-Cabot et al. [41], the GCM predictions are an excellent match to the experimental compression curves. Two specific points can be made from inspection of Fig. 20a. Firstly, the values of $p^{*}$ at which full saturation is predicted by the GCM during either wetting or loading (see points $S_{1}, S_{2}, S_{3}$ and $\mathrm{S}_{4}$ ) correspond to states on a unique saturated isotropic ncl, because mechanical yielding occurred in all four tests before saturation. Secondly, the influence of plastic volumetric strains on the air-exclusion values of modified suction within the GCM (represented by the saturation line expression of Eq. 4) means that the GCM predicts that, during constant suction loading tests, the value of $p^{*}$ required to achieve full saturation is higher for tests conducted at higher values of suction (compare $S_{1}, S_{2}, S_{3}$ and $\mathrm{S}_{4}$ in Fig. 20a), and this is also apparent in the corresponding values of mean net stress $\bar{p}$ (see $\mathrm{S}_{1}, \mathrm{~S}_{2}, \mathrm{~S}_{3}$ and $\mathrm{S}_{4}$ in Fig. 20b). This pattern of response is consistent with the 
few experimental compression paths available that approximately reach full saturation (e.g. [35, 47]).

Inspection of Fig. 20b shows that the experimental results and model predictions appear significantly more confusing when plotted in terms of mean net stress $\bar{p}$ instead of in terms of mean Bishop's stress $p^{*}$ (as in Fig. 20a). In particular, when plotted in terms of $\bar{p}$, the saturated ncl no longer appears as a unique line, with the saturated normal compression line for each nonzero value of suction offset horizontally from the saturated normal compression line for zero suction by the corresponding value of suction. This is simply because the saturated mean effective stress $p^{\prime}$ is given by $p^{\prime}=p-u_{\mathrm{w}}=\bar{p}+s$.

The net stress tensor $\bar{\sigma}_{i j}$ and suction $s$ are often the controlled stress variables in an experiment involving unsaturated conditions, and hence, they are very useful for the study of unsaturated soil behaviour. However, $\bar{\sigma}_{i j}$ and $s$ are no longer relevant mechanical stress variables once the soil is saturated, because air is no longer present in the soil (in the form of gas) once $S_{r}=1$, and the pore air pressure $u_{\mathrm{a}}$ (which appears in $\bar{\sigma}_{i j}$ and $s$ ) is therefore no longer meaningful. Additionally, as anticipated in Gens [27], the use of $\bar{\sigma}_{i j}$ and $s$ as stress state variables of a model makes it very difficult to model correctly transitions between saturated and unsaturated states, because when the air-exclusion and air-entry values of suction are nonzero, the net stress is not equal to the saturated effective stress.

\subsection{Constant volume wetting tests on compacted London clay [45]}

The final set of experimental tests used to examine transitions from unsaturated to saturated states are the constant volume wetting tests on compacted London clay carried out by Monroy [45]. The basic properties of this compacted clay are: liquid limit $83 \%$, plastic limit $29 \%$ and unit weight of solids $27.0 \mathrm{kN} / \mathrm{m}^{3}$ [45]. From these constant volume wetting tests, the experiment conducted at the largest dry density (i.e. $v=1.822$ ) is especially informative and has, therefore, been digitalised in Fig. 21, together with another constant volume wetting test conducted at a lower dry density (i.e. $v=1.952$ ). The experiments were carried out in a suction-controlled oedometer apparatus with measurement of radial stresses [45], so that the mean net stress $\bar{p}$ could be monitored as the suction $s$ was reduced. The experimental values of $S_{r}$ and $v$ were used to calculate corresponding values of mean Bishop's stress $p^{*}$ and modified suction $s^{*}$ (see Eqs. 1,2). The stress paths for the final sections of the two constant volume wetting tests are plotted in Fig. 21 in both the $s^{*}: p^{*}$ plane (Fig. 21a) and the $s: \bar{p}$ plane (Fig. 21b).
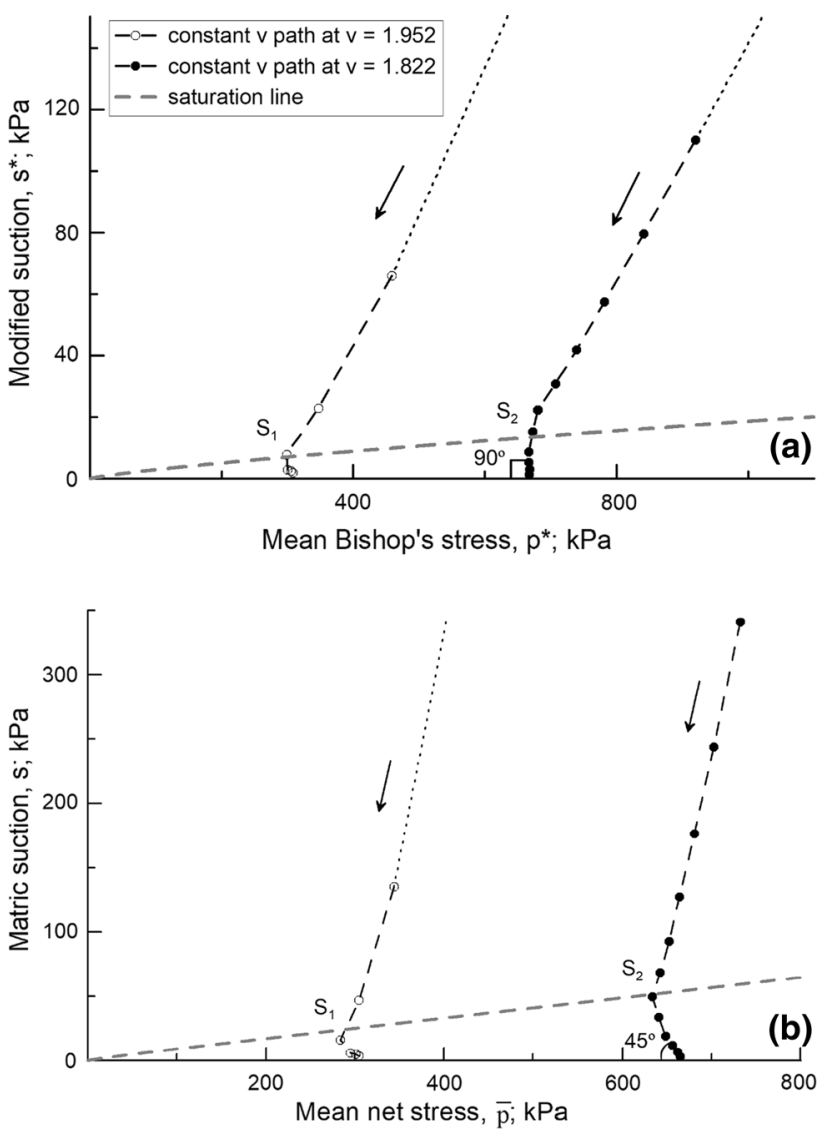

Fig. 21 Experimental constant volume stress paths on compacted London clay [45]: a $s^{*}$ against $p^{*} ; \mathbf{b} s$ against $\bar{p}$

Particularly interesting is the change in behaviour observed at points $S_{1}$ and $S_{2}$ in Fig. 21. According to Monroy [45], both stress states practically correspond to full saturation $\left(S_{r}\right.$ above 0.95). This indicates that the values of modified suction (or matric suction) at $S_{1}$ and $S_{2}$ correspond, approximately, to the air-exclusion point for the given value of dry density or, in the context of the GCM, for the current state of plastic volumetric strain. The value of modified suction at air-exclusion was greater for the sample tested at the higher dry density (i.e. the sample that had been subjected to the larger plastic volumetric strain), consistent with the predicted form of the saturation line in the GCM (Eq. 4).

From points $\mathrm{S}$ onwards, the experimental value of mean Bishop's stress $p^{*}$ (now approximately equal to the mean effective stress, because $S_{r} \cong 1$ ) remained almost constant with decreasing suction (see Fig. 21a). This final vertical section of stress path in the $s^{*}: p^{*}$ plane converts to a stress path at $45^{\circ}$ in the $s: \bar{p}$ plane (Fig. 21b).

The forms of experimental stress path shown in Fig. 21 are exactly what would be predicted by the GCM for constant volume wetting of samples on the WR and $M$ yield surfaces. While the soil is unsaturated, the GCM predicts 
that the stress path in the $s^{*}: p^{*}$ plane would be very similar in shape to the MW curve (see Fig. 21a). The predicted stress path during this unsaturated stage would not be identical to the MW curve, because a small amount of yielding would be required on the $\mathrm{M}$ yield surface, corresponding to a small expansion of the MW curve, to produce a small positive plastic volumetric strain, to exactly offset the negative elastic volumetric strain caused by the reduction of $p^{*}$. Once the soil is saturated (beyond $\mathrm{S}_{1}$ or $\mathrm{S}_{2}$ ), the GCM predicts that the value of $p^{*}$ would remain constant (a vertical stress path in the $s^{*}: p^{*}$ plane, see Fig. 21a), corresponding to no yielding on the $\mathrm{M}$ yield surface (i.e. no plastic volumetric strain) and no elastic volumetric strain. This final constant $p^{*}$ section of the predicted stress path, once the soil is saturated, would correspond to a stress path at $45^{\circ}$ in the $s: \bar{p}$ plane (Fig. 21b).

\section{Conclusions}

During drying paths soils remain fully saturated when the matric suction $s$ is lower than the air-entry value, and during wetting or loading paths soils are fully saturated when $s$ is lower than the air-exclusion value. Air-entry and air-exclusion values of suction for a given soil are not constant, but depend upon the dry density of the soil or the previous history of mechanical yielding (i.e. the amount of plastic volumetric strain).

When the soil is in a saturated state, at a suction less than the relevant air-entry or air-exclusion value, the net stress tensor $\bar{\sigma}_{i j}$ will only be equal to the saturated effective stress tensor $\sigma_{i j}^{\prime}$ when $s=0$ (because $\bar{\sigma}_{i j}+s \cdot \delta_{i j}=\sigma_{i j}^{\prime}$ where $\delta_{i j}$ is the Kronecker delta). Under saturated conditions with $s>0$, the net stress and the saturated effective stress will be different, with the potential magnitude of this difference being large if the air-entry and air-exclusion values of suction are high (this will be the case for fine-grained soils, particularly when compressed to high dry density). For these saturated conditions with nonzero suction, representation of the mechanical response of a soil in terms of the net stress tensor (rather than the saturated effective stress tensor) will potentially be in conflict with Terzaghi's effective stress principle for saturated soils, because net stress is no longer meaningful for saturated conditions. Furthermore, if saturated conditions occur at nonzero values of $s$, the saturated normal compression line no longer appears as a unique line when plotted in terms of mean net stress $\bar{p}$. This complicates the use of conventional elasto-plastic constitutive models expressed in terms of $\bar{\sigma}_{i j}$ and $s$ in situations where $S_{r}=1$ and matric suction is not zero.

This paper demonstrates that all this ambiguity can be removed if the constitutive model uses the Bishop's stress tensor $\sigma_{i j}^{*}$ to represent the mechanical behaviour, with degree of saturation $S_{r}$ also influencing mechanical yielding and the condition $S_{r}=1$ (rather than $s=0$ ) representing transitions to saturated conditions within the model. For $S_{r}=1$, the Bishop's stress tensor $\sigma_{i j}^{*}$ is always equal to the saturated effective stress tensor (i.e. $\sigma_{i j}^{*}=\sigma_{i j}^{\prime}$ ), even if suction is not zero.

The paper demonstrates, through model simulations and comparison with experimental data from the literature, that the Glasgow Coupled Model (GCM), a coupled elastoplastic constitutive model covering both mechanical and retention behaviour, represents transitions between unsaturated and saturated behaviour in a consistent fashion. Key aspects of the GCM are the use of Bishop's stress tensor for mechanical behaviour, the additional influence of $S_{r}$ on mechanical yielding, inclusion of hysteresis in the retention behaviour, and the role of plastic volumetric strains (and not total volumetric strains) in the description of the water retention response.

Within the paper, GCM simulations are compared with experimental data from the literature involving transitions between saturated and unsaturated conditions. Air-drying tests on reconstituted soil samples of clayey silt with different values of saturated pre-consolidation stress [13] are used to explore transitions from saturated to unsaturated conditions. Transitions in the reverse direction (from unsaturated to saturated conditions) are explored using constant water content loading tests on the same reconstituted clayey silt [13], wetting and isotropic loading tests on compacted Speswhite kaolin [63] and constant volume wetting tests on compacted London clay [45]. The success of the GCM in representing consistently both saturated and unsaturated responses, including realistic representation of the stress states at de-saturation and at saturation, demonstrates the potential of this coupled formulation for modelling boundary value problems involving saturated and unsaturated conditions.

Acknowledgements This research has benefitted from the MarieSkłodowska Curie project "COUPLED" funded from the H2020 programme of the EC (MSCA-IF-2015-706712) as well as from the "MECHANICS OF HARD SOILS AND SOFT ROCKS" project funded from the DP programme of the ARC (ARC-DP-2015150103396). Support from a New Staff Grant (G-1301107) of the University of Newcastle (Australia) and from the project "TERRE" (ETN-GA-2015-675762) of the EU are also acknowledged.

Open Access This article is distributed under the terms of the Creative Commons Attribution 4.0 International License (http:// creativecommons.org/licenses/by/4.0/), which permits unrestricted use, distribution, and reproduction in any medium, provided you give appropriate credit to the original author(s) and the source, provide a link to the Creative Commons license, and indicate if changes were made. 


\section{Appendix}

The Glasgow Coupled Model (GCM) predicts that isotropic normal compression states in experimental tests involving plastic volumetric strains and plastic increases in $S_{r}$ will correspond to points at the intersection of $\mathrm{M}$ and WR yield surfaces. For these states, the model predicts unique unsaturated isotropic normal compression planar surfaces for $v$ (in $v: \ln p^{*}: \ln s^{*}$ space) and also for $S_{r}$ (in $S_{r}: \ln p^{*}: \ln s^{*}$ space). The specific mathematical forms of these two planar surfaces are given below for the case with $\kappa_{\mathrm{s}}=0$ (full details of their derivation can be found in [41]:

$v=N^{*}-\lambda^{*} \ln p^{*}+k_{1}^{*} \ln s^{*}$

$S_{r}=\Omega^{*}-\lambda_{\mathrm{s}}^{*} \ln s^{*}+k_{2}^{*} \ln p^{*}$

where $N^{*}$ and $\Omega^{*}$ are their respective intercepts. The expressions of their respective gradients $\lambda^{*}$ and $k_{1}^{*}$ or $\lambda_{\mathrm{s}}^{*}$ and $k_{2}^{*}$ are a combination of the soil parameters of the model [41]:

$\lambda^{*}=\frac{\lambda-k_{1} k_{2} \kappa}{1-k_{1} k_{2}}$

$k_{1}^{*}=k_{1} \frac{(\lambda-\kappa)}{\left(1-k_{1} k_{2}\right)}$

$\lambda_{\mathrm{s}}^{*}=\frac{\lambda_{\mathrm{s}}}{1-k_{1} k_{2}}$

$k_{2}^{*}=k_{2} \frac{\lambda_{\mathrm{s}}}{\left(1-k_{1} k_{2}\right)}$

Combining the expression of the saturated normal compression line (i.e. $v=N-\lambda \ln p^{\prime}$ ) with the normal compression planar surface for $S_{r}$ (Eq. 6) the following relationship between intercepts $N, N^{*}$ and $\Omega^{*}$ is found [41]:

$\Omega^{*}=1-\frac{\left(N^{*}-N\right) \lambda_{\mathrm{s}}}{k_{1}(\lambda-\kappa)}$

For the particular case of isotropic stress states at the intersection between M and DR surfaces, the GCM predicts two additional planar surfaces whose expressions are:

$v=N^{*}-k_{1}^{*} \ln R-\lambda^{*} \ln p^{*}+k_{1}^{*} \ln s^{*}$

$S_{r}=\Omega^{*}+\lambda_{\mathrm{s}}^{*} \ln R-\lambda_{\mathrm{s}}^{*} \ln s^{*}+k_{2}^{*} \ln p^{*}$

where $R$ gives the fixed ratio between the hardening parameters $s_{2}^{*}$ to $s_{1}^{*}$, defining the position of the DR and WR surfaces, respectively.

\section{References}

1. Al Haj KMA, Standing JR (2016) Soil water retention curves representing two tropical clay soils from Sudan. Géotechnique 66(1):71-84
2. Alonso EE, Gens A, Josa A (1990) A constitutive model for partially saturated soils. Géotechnique 40(3):405-430

3. Alonso EE, Olivella S, Pinyol NM (2005) A review of Beliche Dam. Géotechnique 55(4):267-285

4. Alonso EE, Pereira JM, Vaunat J, Olivella S (2010) A microstructurally based effective stress for unsaturated soils. Géotechnique 60(12):913-925

5. Alonso EE, Olivella S, Soriano A, Pinyol NM, Esteban F (2011) Modelling the response of Lechago earth and rockfill dam. Géotechnique 61(5):387-407

6. Alonso EE, Pinyol NM, Gens A (2013) Compacted soil behaviour: initial state, structure and constitutive modelling. Géotechnique 63(6):463-478

7. Barrera Bucio M (2002) Estudio experimental del comportamiento hidro-mecánico de suelos colapsables. $\mathrm{PhD}$ thesis, Universitat Politècnica de Catalunya, Spain

8. Bishop AW (1959) The principle of effective stress. Teknisk Ukeblad 39:859-863

9. Blight GE (1965) A study of effective stresses for volume change. In: Aitchison GD (ed) Moisture equilibria and moisture changes in the soils beneath covered areas, a symposium in print. Sidney, Australia, pp 259-269

10. Bolzon G, Schrefler BA, Zienkiewicz OC (1996) Elastoplastic soil constitutive laws generalized to partially saturated states. Géotechnique 46(2):279-289

11. Borja RI, White JA (2010) Continuum deformation and stability analyses of a steep hillside slope under rainfall infiltration. Acta Geotech 5:1-14

12. Borja RI, Liu X, White JA (2012) Multiphysics hillslope processes triggering landslides. Acta Geotech 7:261-269

13. Boso M (2005). Shear strenght beahviour of a reconstituted partially saturated clayey silt. $\mathrm{PhD}$ thesis, Università degli Studi di Trento, Italy

14. Burland JB (1965) Some aspects of the mechanical behaviour of partially saturated soils. In: Aitchison GD (ed) Moisture equilibria and moisture changes in the soils beneath covered areas, a symposium in print, Sidney, Australia, pp 270-278

15. Burland JB, Ridley AM (1996) The importance of suction in soil mechanics. In: Proceedings of 12th south-east Asian conference on soil mechanics and foundation engineering, Kuala Lumpur, vol 2, pp 27-49

16. Caruso A, Tarantino A (2004) A shearbox for testing unsaturated soils from medium to high degrees of saturation. Géotechnique 54(4):281-284

17. Cunningham MR (2000) The mechanical behavior of a reconstituted, unsaturated soil. PhD thesis, Imperial College of London, UK

18. Cunningham MR, Ridley AM, Dineen K, Burland JB (2003) The mechanical behaviour of a reconstituted unsaturated silty clay. Géotechnique 53(2):183-194

19. Della Vecchia G, Jommi C, Romero E (2013) A fully coupled elastic-plastic hydro-mechanical model for compacted soils accounting for clay activity. Int J Numer Anal Methods Geomech 37(5):503-535

20. D’Onza F, Wheeler SJ, Gallipoli D, Barrera M, Hofmann M, Lloret-Cabot M, Lloret A, Mancuso C, Pereira J-M et al (2015) Benchmarking selection of parameter values for the Barcelona basic model. Eng Geol 196:99-118

21. Fleureau J-M, Kheirbek-Saoud S, Soemitro R, Taibi S (1993) Behaviour of clayey soils on drying-wetting paths. Can Geotech J 30(2):287-296

22. Fredlund DG, Morgenstern NR, Widger RA (1978) The shear strength of unsaturated soil. Can Geotech J 15:313-321

23. Gallipoli D (2000) Constitutive and numerical modelling of unsaturated soils. PhD thesis, University of Glasgow, UK 
24. Gallipoli D, Gens A, Sharma R, Vaunat J (2003) An elastoplastic model for unsaturated soil including the effect of saturation degree on mechanical behaviour. Géotechnique 53(1):123-135

25. Gallipoli D, Wheeler SJ, Karstunen M (2003) Modelling the variation of degree of saturation in a deformable unsaturated soil. Géotechnique 53(1):105-112

26. Gallipoli D, Gens A, Chen G, D’Onza F (2008) Modelling unsaturated soil behaviour during normal consolidation and at critical state. Comput Geotech 35(6):825-834

27. Gens A (1996) Constitutive modelling: application to compacted soils. In: Alonso E, Delage P (eds) Unsaturated soils, vol 3. Balkema, Rotterdam, pp 1179-1200

28. Gens A (2010) Soil-environment interactions in geotechnical engineering. Géotechnique 60(1):3-74

29. Gens A (2010) Some issues in constitutive modelling of unsaturated soils. In: Buzzi O, Fityus SG, Sheng D (eds) Unsaturated soils-theoretical and numerical advances in unsaturated soil mechanics, vol 1. CRC Press, Boca Raton, pp 613-626

30. Houlsby GT (1997) The work input to an unsaturated granular material. Géotechnique 47(1):193-196

31. Jommi C (2000) Remarks on the constitutive modelling of unsaturated soils. In: Tarantino A, Mancuso C (eds) Experimental evidence and theoretical approaches in unsaturated soils. Balkema, Rotterdam, pp 139-153

32. Jommi C, Di Prisco C (1994) A simple theoretical approach for modelling the mechanical behaviour of unsaturated granular soils (in Italian). In: Il ruolo dei fluidi in ingegneria geotecnica. Proceedings of Italian conference on Mondovi, vol. 1 (II), pp $167-188$

33. Josa A, Balmaceda A, Alonso EE, Gens A (1992) An elastoplastic model for partially saturated soils exhibiting a maximum of collapse. In: Owen DR, Oñate E, Hinton E (eds) Computational plasticity and fundamentals and applications. Pineridge Press, Swansea, pp 815-826

34. Jotisankasa A (2005) Collapse behaviour of a compacted silty clay. $\mathrm{PhD}$ thesis, Imperial College of London, UK

35. Jotisankasa A, Ridley A, Coop M (2007) Collapse behavior of a compacted silty clay in the suction-monitored oedometer apparatus. J Geotech Geoenviron Eng ASCE 133(7):867-877

36. Khalili N, Habte MA, Zargarbashi S (2008) A fully coupled flow deformation model for cyclic analysis of unsaturated soils including hydraulic and mechanical hysteresis. Comput Geotech 35(6):872-889

37. Lloret M (2011) Numerical modelling of coupled behaviour in unsaturated soils. $\mathrm{PhD}$ thesis, University of Strathclyde and University of Glasgow, UK

38. Lloret-Cabot M, Sánchez M, Wheeler SJ (2013) Formulation of a three-dimensional constitutive model for unsaturated soils incorporating mechanical-water retention couplings. Int J Numer Anal Methods Geomech 37:3008-3035

39. Lloret-Cabot M, Wheeler SJ, Sánchez M (2014) Unification of plastic compression in a coupled mechanical and water retention model for unsaturated soils. Can Geotech J 51(12):1488-1493

40. Lloret-Cabot M, Wheeler SJ, Pineda JA, Sheng D, Gens A (2014) Relative performance of two unsaturated soil models using different constitutive variables. Can Geotech J 51(12):1423-1437

41. Lloret-Cabot M, Wheeler SJ, Sánchez M (2017) A unified mechanical and retention model for saturated and unsaturated soil behaviour. Acta Geotech 12(1):1-21

42. Marinho FAM (1994) Shrinkage behaviour of some plastic soils. $\mathrm{PhD}$ thesis, Imperial College of London, UK

43. Mašin D (2010) Predicting the dependency of a degree of saturation on void ratio and suction using effective stress principle for unsaturated soils. Int J Numer Anal Methods Geomech 34:73-90
44. Menin A, Salomoni VA, Saltgiuliana R, Simoni L, Gens A, Schrefler BA (2008) A mechanism contributing to subsidence above gas reservoirs and its application to a case study. Int $\mathbf{J}$ Comput Methods Eng Sci Mech 9(5):270-287

45. Monroy R (2006) The influence of load and suction changes on the volumetric behaviour of compacted London Clay. $\mathrm{PhD}$ thesis, Imperial College of London, UK

46. Monroy R, Zdravkovic L, Ridley AM (2010) Evolution of microstructure in compacted London Clay during wetting and loading. Géotechnique 60(2):105-119

47. Monroy R, Zdravkovic L, Ridley AM (2015) Mechanical behaviour of unsaturated expansive clay under K0 conditions. Eng Geol 197(30):112-131

48. Ng CWW, Pang YW (2000) Influence of stress state on soilwater characteristics and slope stability. J Geotech Eng ASCE 126(2):157-166

49. Nuth M, Laloui L (2008) Advances in modelling hysteretic water retention curve in deformable soils. Comput Geotech 35(6):835-844

50. Raveendiraraj A (2009) Coupling of mechanical behaviour and water retention behaviour in unsaturated soils. $\mathrm{PhD}$ thesis, University of Glasgow, UK

51. Romero E (1999) Characterisation and thermo-hydro-mechanical behaviour of unsaturated Boom clay: an experimental study. PhD thesis, Universitat Politècnica de Catalunya, Spain

52. Romero E (2013) A microstructural insight into compacted clayey soils and their hydraulic properties. Eng Geol 165:3-19

53. Romero E, Vaunat J (2000) Retention curves of deformable clays. In: Tarantino A, Mancuso C (eds) Experimental evidence and theoretical approaches in unsaturated soils. Balkema, Rotterdam, pp 91-106

54. Romero E, Gens A, Lloret A (1999) Water permeability, water retention and microstructure of unsaturated compacted Boom clay. Eng Geol 54:117-127

55. Romero E, Della Vecchia G, Jommi C (2011) An insight into the water retention properties of compacted clayey soils. Géotechnique 61(4):313-328

56. Roscoe KH, Burland JB (1968) On the generalised stress-strain behavior of 'wet' clay. In: Heyman J, Leckie FA (eds) Engineering plasticity. Cambridge University Press, Cambridge, pp 535-609

57. Salager S, Nuth M, Ferrari A, Laloui L (2013) Investigation into water retention behaviour of deformable soils. Can Geotech J 50:200-208

58. Schrefler BA (1984) The finite element method in soil consolidation (with applications to surface subsidence). $\mathrm{PhD}$ thesis, University College of Swansea, UK

59. Sharma RS (1998) Mechanical behaviour of unsaturated highly expansive clays. PhD thesis, University of Oxford, UK

60. Sheng D (2011) Review of fundamental principles in modelling unsaturated soil behaviour. Comput Geotech 38(6):757-776

61. Sheng D, Zhou A (2011) Coupling hydraulic with mechanical models for unsaturated soils. Can Geotech J 48:826-840

62. Sheng D, Fredlund DG, Gens A (2008) A new modelling approach for unsaturated soils using independent stress variables. Can Geotech J 45:511-534

63. Sivakumar V (1993) A critical state framework for unsaturated soil. PhD thesis, University of Sheffield, UK

64. Sivakumar V, Wheeler SJ (2000) Influence of compaction on the mechanical behaviour of an unsaturated compacted clay. Part 1: wetting and isotropic compression. Géotechnique 50(4):359-368

65. Song X, Borja RI (2014) Mathematical framework for unsaturated flow in the finite deformation range. Int J Numer Methods Eng 14:658-682 
66. Sun DA, Sheng D, Xu Y (2007) Collapse behaviour of unsaturated compacted soil with different initial densities. Can Geotech J 44:673-686

67. Tamagnini R (2004) An extended Cam-clay model for unsaturated soils with hydraulic hysteresis. Géotechnique 54(3):223-228

68. Tarantino A (2009) A water retention model for deformable soils. Géotechnique 59(9):751-762

69. Tarantino A, Gallipoli D, Augarde CE, De Gennaro V, Gomez R, Laloui L, Mancuso C, El Mountassir G, Munoz J, Pereira J-M, Peron H, Pisoni G, Romero E, Raveendiraraj A, Rojas JC, Toll DG, Tombolato S, Wheeler S (2011) Benchmark of experimental techniques for measuring and controlling suction. Géotechnique 61(4):303-312

70. Toll DG (1988) The behaviour of unsaturated naturally occurring gravel. $\mathrm{PhD}$ thesis, Imperial College of London, UK

71. Tsiampousi A, Zdravkovic L, Potts DM (2013) Variation with time of the factor of safety of slopes excavated in unsaturated soils. Comput Geotech 48(2):167-178

72. Tsiampousi A, Zdravkovic L, Potts DM (2016) Soil-atmosphere interaction in unsaturated cut slopes. In: Delage P, Ghabezloo S, Tang A-M, Cui Y-J, Pereira J-M (eds) Proceedings of 3rd European conference on unsaturated soils. EDP Sciences, Paris

73. Vanapalli SK, Fredlund DG, Pufahl DE, Clifton AW (1996) Model for the prediction of shear strength with respect to soil suction. Can Geotech J 33(3):379-392
74. Vaunat J, Romero E, Jommi C (2000) An elastoplastic hydromechanical model for unsaturated soils. In: Tarantino A, Mancuso C (eds) Experimental evidence and theoretical approaches in unsaturated soils. Balkema, Rotterdam, pp 121-138

75. Vicol T (1990) Propriétés mécaniques et hydrauliques d'un limon non saturé - Conséquences sur la modélisation. PhD thesis, Ecole Nationale des Ponts et Chaussées, France

76. Vilar OM, Rodrigues RA (2011) Collapse behavior of soil in a Brazilian region affected by a rising water table. Can Geotech J 48(2):226-233

77. Wheeler SJ, Sivakumar V (1995) An elasto-plastic critical state framework for unsaturated soil. Géotechnique 45(1):35-53

78. Wheeler SJ, Sharma RS, Buisson MSR (2003) Coupling of hydraulic hysteresis and stress-strain behaviour in unsaturated soils. Géotechnique 53(1):41-54

79. Wong HN, Ho KKS (1997) The 23 July 1994 landslide at Kwun Lung Lau, Hong Kong. Can Geotech J 34(6):825-840

80. Zhou A, Sheng D (2015) An advanced hydro-mechanical constitutive model for unsaturated soils with different initial densities. Comput Geotech 63:46-66

81. Zhou A, Huang R, Sheng D (2016) Capillary water retention curve and shear strength of unsaturated soils. Can Geotech $\mathrm{J}$ 53:974-987 